\title{
Long-Run Risk through Consumption Smoothing
}

\author{
Georg Kaltenbrunner* and Lars Lochstoer ${ }^{\dagger, \ddagger}$ \\ First draft: 31 May 2006
}

December 15, 2006

\begin{abstract}
We show that a standard production economy model where consumers have EpsteinZin preferences can jointly explain the low volatility of consumption growth and a high market price of risk with a low coefficient of relative risk aversion (5). Endogenous consumption smoothing increases the price of risk in this economy as it induces highly persistent time-variation in expected aggregate consumption growth (long-run risk), even though technology follows a random walk. As is usual in production economy models, the volatility of equity returns is quite low. We propose an extension where we calibrate the wage process to the data and show that this brings the equity volatility, and thus the equity premium, much closer to historical values. The model identifies an observable proxy for otherwise hard to measure expected consumption growth. Using this proxy, we test and find support for key predictions of our model in the time-series of consumption growth and the cross-section of stock returns.
\end{abstract}

${ }^{*}$ London Business School. Mailing address: IFA, 6 Sussex Place Regent's Park, London, United Kingdom NW1 4SA. Email: gkaltenbrunner.phd2003@london.edu

${ }^{\dagger}$ Corresponding author. London Business School. Mailing address: IFA, 6 Sussex Place Regent's Park, London, United Kingdom NW1 4SA. Email: llochstoer@london.edu

${ }^{\ddagger}$ The authors are grateful for helpful comments from Viral Acharya, Mike Chernov, Wouter den Haan, Vito Gala, Francisco Gomes, Alexander Kurshev, Ebrahim Rahbari, Bryan Routledge, Raman Uppal, Stanley Zin, and seminar participants at the ASAP conference at Oxford University, Carnegie-Mellon University, CEPR Gerzensee, HEC Lausanne, London Business School, and Tilburg University. 


\section{Introduction}

Long-run consumption risk has recently been proposed as a mechanism for explaining important asset price moments such as the Sharpe ratio of equity market returns, the equity premium, the level and volatility of the risk-free rate, and the cross-section of stock returns (see Bansal and Yaron, 2004, Hansen, Heaton and Li, 2005, and Parker and Julliard, 2005). In this paper, we demonstrate how long-run consumption risk arises endogenously in a standard production economy framework and how this additional risk factor can help these models to jointly explain the dynamic behavior of consumption, investment, and asset prices. $^{1}$

We assume that consumers have Epstein-Zin preferences and dislike negative shocks to future economic growth prospects. Unlike the case of power utility preferences, where risk is only associated with the shock to realized consumption growth, investors in this economy also dislike negative shocks to expected consumption growth and consequentially demand a premium for holding assets correlated with this shock. ${ }^{2}$ The latter source of risk has been labelled "long-run risk" in previous literature (Bansal and Yaron, 2004). We show that even when the log technology process is a random walk, endogenous consumption smoothing increases the price of risk in the production economy model exactly because it increases the amount of long-run risk in the economy. The long-run risk, in turn, arises because consumption smoothing induces highly persistent time-variation in expected consumption growth rates.

Why does the consumer optimally choose a consumption process that leads to a high price of risk? The price of risk is related to risk across states, while the agent maximizes the level of expected utility which also is a function of substitution across time. The agent thus trades off the benefit of shifting consumption across time with the cost of higher volatility of marginal utility across states. Asset prices in the production economy reflect the optimal outcome of this trade-off. A higher elasticity of intertemporal substitution results in more substitution across time at the expense of additional risk across states, and thus a higher price of risk, higher Sharpe ratios, and a lower and less volatile risk-free rate.

\footnotetext{
${ }^{1}$ For extensive discussions of the poor performance of standard production economy models in terms of jointly explaining asset prices and macroeconomic moments, refer to Rouwenhorst (1995), Lettau and Uhlig (2000), Uhlig (2004), and Cochrane (2005), amongst others.

${ }^{2}$ Epstein-Zin preferences provide a convenient separation of the elasticity of intertemporal substitution $(\psi)$ from the coefficient of relative risk aversion $(\gamma)$, which are restricted to $\gamma=\frac{1}{\psi}$ in the power utility case. If $\gamma>\frac{1}{\psi}$, investors prefer early resolution of uncertainty (Duffie and Epstein, 1992) and, thus, are averse to shocks to expected consumption growth (Bansal and Yaron, 2004).
} 
In equilibrium, time-varying expected consumption growth turns out to be a small, but highly persistent, fraction of realized consumption growth. When the model is calibrated to fit standard macroeconomic moments, the endogenous expected consumption growth rate process is quantitatively very close to the exogenous processes that have been specified in the recent asset pricing literature (see, e.g., Bansal and Yaron, 2004). Note that this result is of particular interest since it is very difficult to empirically distinguish a small predictable component of consumption growth from i.i.d. consumption growth given the short sample of data we have available (see Harvey and Shepard, 1990, and Hansen, Heaton and Li, 2005, amongst others). Bansal and Yaron (2004), for instance, calibrate a process for consumption growth with a highly persistent trend component and demonstrate that their process can match a number of moments of aggregate consumption growth. In lieu of robust empirical evidence on this matter, the model presented in this paper provides a theoretical justification for the previously proposed long-run risk dynamics of aggregate consumption growth based on a standard production economy setup. We conclude that simple consumption smoothing in an economy with i.i.d. technology growth naturally induces long-run consumption risk. Long-run consumption risk is therefore not an esoteric assumption for aggregate consumption dynamics. On the contrary, it is the natural assumption, given our standard theoretical models, for exogenous consumption growth processes in exchange economy models.

The persistence of the technology shocks is crucial for the asset pricing implications of long-run risk in the model. In short, permanent shocks lead to time-varying expected consumption growth that increases the price of risk in the economy, while transitory shocks lead to time-varying expected consumption growth that decreases the price of risk. The intuition for this is as follows. A permanent positive shock to productivity implies a permanently higher optimal level of capital. As a result, investors increase investment in order to build up a higher capital stock. High investment today implies low current consumption, but high future consumption. Thus, expected consumption growth is high. The higher investors' elasticity of intertemporal substitution, the more willing investors are to substitute consumption today for higher consumption in the future, and the stronger this effect is. Since agents in this economy dislike negative shocks to future economic growth prospects, both shocks to expected consumption growth and realized consumption growth are risk factors. Furthermore, the shocks are positively correlated and thus reinforce each other. In this case, endogenous consumption smoothing increases the price of risk in the economy. On the other hand, if shocks to technology are transitory, the endogenous long-run risk decreases the price of risk in the economy. A transitory, positive shock to technology implies that 
technology is expected to revert back to its long-run trend. Thus, if realized consumption growth is high, expected future long-run consumption growth is low as consumption also reverts to the long-run trend. The shock to expected future consumption growth is in this case negatively correlated with the shock to realized consumption growth, so the long-run risk component acts as a hedge for shocks to current consumption. ${ }^{3}$ The overall price of risk in the economy is then decreasing in the magnitude of long-run risk. ${ }^{4}$

We evaluate the quantitative effects of transitory versus permanent technology shocks on aggregate macroeconomic and financial moments with calibrated versions of our model. If technology shocks are permanent, the model can match the high historical Sharpe ratio of equities and the level and volatility of the risk-free rate with a low coefficient of relative risk aversion. The equity premium, however, is still too low in the baseline model, which is a well-known problem of standard production economy models (see, e.g., Jermann, 1998). We address this problem by calibrating the wage process of the model to the data. This brings the endogenous dividend process closer to the data, and as a result the equity premium as well as the equity return volatility increase by an order of magnitude to levels close to empirical values. Thus, the standard real business cycle model (without habit preferences) has the clear potential to jointly explain asset prices and macroeconomic time series.

The production economy model relates the aggregate level of technology (total factor productivity), consumption, and investment to the dynamic behavior of aggregate consumption growth. We use this link to derive new testable implications. Our model implies that the ratio of total factor productivity to consumption is a good proxy for the otherwise hard to measure expected consumption growth rate. We find empirical support for this by showing that the ratio of log total factor productivity to consumption forecasts future consumption growth over long horizons. We furthermore test a linear approximation of the model on the cross-section of stock returns and show, using the above proxy, that shocks to expected consumption growth are a priced risk factor that substantially improves the ability of the Consumption CAPM to explain the cross-section of stock returns.

We proceed as follows. We start by providing an overview of related literature. Then we

\footnotetext{
${ }^{3}$ This description is intentionally loose to emphasize the intuition. The consumption response to transitory technology shocks is actually hump-shaped. Thus, a positive shock to realized consumption growth is followed by high expected consumption growth in the near term, but lower expected consumption growth in the long term - the negative correlation arises at lower frequencies. The low frequency effect dominates for standard values of the time-discounting parameter and leads to a lower price of risk unless the transitory shocks are extremely persistent.

${ }^{4}$ If, on the other hand, agents like long-run risk, endogenous long-run risk would increase the price of risk when technology shocks are transitory and decrease the price of risk when technology shocks are permanent.
} 
give a preview of our results and develop and interpret the model. In Section 5 we calibrate and solve the model, demonstrate and interpret results, and provide intuition. In Section 6 we test some empirical implications of our model. Section 7 concludes.

\section{Related Literature}

This paper is mainly related to three strands of the literature: the literature on consumption smoothing, the literature on long-run risk, and the literature that aims to jointly explain macroeconomic aggregates and asset prices.

It is well-known that (risk averse) agents want to smooth consumption over time. The permanent income hypothesis of Friedman (1957) is the classic reference. Hall (1978) is a seminal empirical investigation of this hypothesis. Hall shows that consumption should approximately follow a random walk and finds support for this in the data. The results in our paper are consistent with Hall: We also find that consumption should be very close to a random walk. But, different from Hall, we emphasize that consumption growth has a small, highly persistent, time-varying component. Time-variation in expected growth rates, arising from consumption smoothing in production economy models, has been pointed out before. For example, Den Haan (1995) demonstrates that the risk-free rate in production economy models is highly persistent (close to a random walk) even when the level of technology is i.i.d.

Bansal and Yaron (2004) show that a small, persistent component of consumption growth can have quantitatively important implications for asset prices if the representative agent has Epstein-Zin (1989) preferences. Bansal and Yaron term this source of risk "long-run risk" and show that it can explain many aspects of asset prices. They specify exogenous

processes for dividends and consumption with a slow-moving expected growth rate component and demonstrate that the ensuing long-run consumption risk greatly improves their model's performance with respect to asset prices without having to rely on, e.g., habit formation and the high relative risk aversion such preferences imply. We show that the process for consumption Bansal and Yaron assume as exogenous can be generated endogenously in a standard production economy model with Epstein-Zin preferences and the same preference parameters Bansal and Yaron use. Since it is very difficult to empirically distinguish between i.i.d. consumption growth and consumption growth with a very small, highly persistent time-varying component, this result is of particular importance for the Bansal and 
Yaron framework. Hansen, Heaton and Li (2005) emphasize this point in their study of the impact of long-run risk on the cross-section of stock returns. We also consider the implications for aggregate investment and output, which Bansal and Yaron abstract from, and we endogenize the aggregate dividend process. A recent paper that generates interesting consumption dynamics is due to Panageas and Yu (2006). These authors focus on the impact of major technological innovations and real options on consumption and the cross-section of asset prices. They assume, as do we, the technology process to be i.i.d. The major technological innovations, however, are assumed to occur at a very low frequency (about 20 years), and are shown to carry over into a small, highly persistent component of aggregate consumption. In that sense, Panageas and $\mathrm{Yu}$ assume, contrary to us, the low frequency of the predictable component of consumption growth. Moreover, time-variation in expected consumption growth (long-run risk) is not itself a priced risk factor in the Panageas and Yu model because the representative agent does not have Epstein-Zin (1989) preferences, but external ratio-habit as in Abel (1990). Finally, since investment in their model means paying a "gardener" to plant a tree, their model does not have a clear separation of investment and labor income. Parker and Julliard (2005) find that the CCAPM can explain the cross-section of stock returns only when consumption growth is measured over longer horizons. This is consistent both with frictions to consumption adjustment and the presence of long-run risks.

There are quite a few papers before Bansal and Yaron (2004) that emphasize a small, highly persistent component in the pricing kernel. An early example is Backus and Zin (1994) who use the yield curve to reverse-engineer the stochastic discount factor and find that it has high conditional volatility and a persistent, time-varying conditional mean with very low volatility. These dynamics are also highlighted in Cochrane and Hansen (1992). This is exactly the dynamic behavior generated endogenously by the models considered in this paper, and as such the paper complements the above earlier studies. The use of Epstein-Zin (1989) preferences provides a justification for why the small, slow-moving timevariation in expected consumption growth generates high volatility of the stochastic discount factor. These preferences have become increasingly popular in the asset pricing literature. By providing a convenient separation between the coefficient of relative risk aversion and the elasticity of intertemporal substitution, they help to jointly explain asset market data and aggregate consumption dynamics. An early implementation is Epstein and Zin (1991), while Malloy, Moskowitz and Vissing-Jorgensen (2005) and Yogo (2006) are more recent, successful examples. 
This paper also makes a contribution to a literature Cochrane (2005) terms 'productionbased asset pricing'. This literature tries to jointly explain the behavior of macroeconomic time series, in particular aggregate consumption, and asset prices. The starting point of this literature is the standard production economy model (standard stochastic growth model) with capital adjustment costs and the observation that this model, while being able to generate realistic processes for consumption and investment, fails markedly at explaining

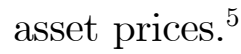

Both Jermann (1998) and Boldrin, Christiano and Fisher (2001) augment the basic production economy framework with habit preferences in order to remedy its shortcomings. Boldrin, Christiano and Fisher also assume a two-sector economy with adjustment frictions across sectors and across time. Boldrin, Christiano and Fisher furthermore endogenize the labor-leisure decision, they assume however that labor can not be adjusted immediately in response to technology shocks. Jermann and in particular Boldrin, Christiano and Fisher succeed to a considerable extent to jointly explain with their models macroeconomic time series and asset prices. However, the price both models pay, typical for simple internal habit specifications, is excessive volatility of the risk-free rate and very high levels of risk aversion. In a sense, their internal habits buy volatility in equity returns with volatility in risk-free rates. Relative to Jermann and Boldrin, Christiano and Fisher our contribution is to demonstrate that the standard production economy model without habit preferences can actually, once appropriately calibrated, jointly explain basic macroeconomic time series as well as important aggregate asset price moments without excessive risk-free rate volatility and high levels of risk aversion.

Tallarini (2000) proposes a model that is closely related to our setup. In essence, Tallarini restricts himself to a special case of our model with the elasticity of intertemporal substitution fixed at unity and no capital adjustment costs. By increasing the coefficient of relative risk aversion to very high levels Tallarini manages to match some asset pricing moments such as the market price of risk (Sharpe ratio) as well as the level of the risk-free rate, while equity premium and return volatilities in his model remain basically zero. We differ from Tallarini in that our focus is on changing the elasticity of intertemporal substitution and the implications for the pricing and existence of long-run risk. Relative to the Tallarini setup we show that (moderate) capital adjustment costs together with an elasticity of intertemporal substitution greater than unity can dramatically improve the model's ability to match asset

\footnotetext{
${ }^{5}$ Cochrane (2005): "[Jermann (1998)] starts with a standard real business cycle (one sector stochastic growth) model and verifies that its asset-pricing implications are a disaster."
} 
pricing moments. We confirm Tallarini's conclusion that the behavior of macroeconomic time series is driven by the elasticity of intertemporal substitution and largely unaffected by the coefficient of relative risk aversion. However, we do not confirm a "separation theorem" of quantity and price dynamics. When we change the elasticity of substitution in our model, both macroeconomic quantity and asset price dynamics are greatly affected.

\section{The Model}

The model is a standard real business cycle model (Kydland and Prescott, 1982, and Long and Plosser, 1983). There is a representative firm with Cobb-Douglas production technology and capital adjustment costs, and a representative agent with Epstein-Zin (1989) preferences. Our objective is to demonstrate how standard production economy models endogenously give rise to long-run consumption risk and that this long-run risk can improve the performance of these models in replicating important moments of asset prices. To that end we keep both production technology as well as the process for total factor productivity as simple and as standard as possible. In particular, we do not assume any propagation mechanisms such as time-to-build. We describe the key components of our model in turn.

The Representative Agent. We assume a representative household whose preferences are in the recursive utility class of Epstein and Zin (1989):

$$
U_{t}\left(C_{t}\right)=\left\{(1-\beta) C_{t}^{\frac{1-\gamma}{\theta}}+\beta\left(E_{t}\left[U_{t+1}^{1-\gamma}\right]\right)^{\frac{1}{\theta}}\right\}^{\frac{\theta}{1-\gamma}}
$$

where $E_{t}$ denotes the expectation operator, $C_{t}$ denotes aggregate consumption, $\beta$ the discount factor, and $\theta=\frac{1-\gamma}{1-1 / \psi}$. Epstein and Zin show that $\gamma$ governs the coefficient of relative risk aversion and $\psi$ the elasticity of intertemporal substitution. These preferences thus have the useful property that it is possible to separate the agent's relative risk aversion from the elasticity of intertemporal substitution, unlike the standard power utility case where $\gamma=\frac{1}{\psi}$. If $\gamma \neq \frac{1}{\psi}$, the utility function is no longer time-additive and agents care about the temporal distribution of risk - a feature that is central to our analysis. We focus on the case where $\gamma>\frac{1}{\psi}$. In this case investors have a preference for early resolution of uncertainty. As a result, investors dislike fluctuations in future economic growth prospects (i.e., fluctuations 
in expected consumption growth). ${ }^{6}$ We discuss this property and its implications in more detail below.

The Stochastic Discount Factor and Risk. The stochastic discount factor, $M_{t+1}$, is the ratio of the representative agent's marginal utility between today and tomorrow: $M_{t+1}=\frac{U^{\prime}\left(C_{t+1}\right)}{U^{\prime}\left(C_{t}\right)}$. Using a recursive argument, Epstein and Zin (1989) show that:

$$
\ln M_{t+1} \equiv m_{t+1}=\theta \ln \beta-\frac{\theta}{\psi} \Delta c_{t+1}-(1-\theta) r_{a, t+1}
$$

where $\Delta c_{t+1} \equiv \ln \frac{C_{t+1}}{C_{t}}$ and $r_{a, t+1} \equiv \ln \frac{A_{t+1}+C_{t+1}}{A_{t}}$ is the return on the total wealth portfolio with $A_{t}$ denoting total wealth at time $t^{7}$ If $\gamma=\frac{1}{\psi}, \theta=\frac{1-\gamma}{1-1 / \psi}=1$, and the stochastic discount factor collapses to the familiar power utility case, where shocks to realized consumption growth are the only source of risk in the economy. However, if $\gamma \neq \frac{1}{\psi}$, the return on the wealth portfolio appears as a risk factor. Persistent time-variation in expected consumption growth (the expected "dividends" on the total wealth portfolio) induces higher volatility of asset returns (Barsky and DeLong, 1993). Thus, the return on any asset is a function of the dynamic behavior of realized and expected consumption growth (Bansal and Yaron, 2004). Depending on the sign of $\theta$ and the covariance between realized consumption growth and the return on the total wealth portfolio, the volatility of the stochastic discount factor (i.e., the price of risk in the economy) can be higher or lower relative to the benchmark power utility case. We show later how this covariance, and thus the amount of long-run risk due to endogenous consumption smoothing, changes with the persistence of the technology shock.

We focus on the case where investors prefer early resolution of uncertainty $\left(\gamma>\frac{1}{\psi}\right)$ and therefore dislike fluctuations in future economic growth prospects. In the appendix, we explain in more detail how a preference for early resolution of uncertainty translates into aversion of time-varying expected consumption growth. We will refer to the volatility of expected future consumption growth rates as "long-run risk".

Technology. There is a representative firm with a Cobb-Douglas production technology:

$$
Y_{t}=\left(Z_{t} H_{t}\right)^{1-\alpha} K_{t}^{\alpha},
$$

\footnotetext{
${ }^{6}$ See the appendix for a discussion of the difference and implications of a preference for early vs. late resolution of uncertainty.

${ }^{7}$ Note that our representative household's total wealth portfolio is composed of the present value of future labor income in addition to the value of the firm.
} 
where $Y_{t}$ denotes output, $K_{t}$ the firm's capital stock, $H_{t}$ the number of hours worked, and $Z_{t}$ denotes the (stochastic) level of aggregate technology. This constant returns to scale and decreasing marginal returns production technology is standard in the macroeconomic literature. We assume households to supply a constant amount of hours worked (following, e.g., Jermann, 1998) and normalize $H_{t}=1{ }^{8}$ The productivity of capital and labor depends on the level of technology, $Z_{t}$, which is the exogenous driving process of the economy. We model $\log$ technology, $z \equiv \ln (Z)$, both as a random walk with drift, and as an $\operatorname{AR}(1)$ with a time trend:

$$
\begin{aligned}
z_{t+1} & =\mu+z_{t}+\sigma_{z} \varepsilon_{t+1} \\
\varepsilon_{t} & \sim N(0,1)
\end{aligned}
$$

or:

$$
\begin{aligned}
z_{t+1} & =\mu t+\varphi z_{t}+\sigma_{z} \varepsilon_{t+1} \\
\varepsilon_{t} & \sim N(0,1),|\varphi|<1
\end{aligned}
$$

Thus, (4) implies that technology shocks are permanent whereas (5) implies that technology shocks are transitory. Both specifications are commonly used in the literature. ${ }^{9}$ We discuss the two specifications separately.

Capital Accumulation and Adjustment Costs. The agent can shift consumption from today to tomorrow by investing in capital. The firm accumulates capital according to the following law of motion:

$$
K_{t+1}=(1-\delta) K_{t}+\phi\left(\frac{I_{t}}{K_{t}}\right) K_{t}
$$

where $I_{t}$ is aggregate investment and $\phi(\cdot)$ is a positive, concave function, capturing the notion that adjusting the capital stock rapidly by a large amount is more costly than adjusting it step by step. We follow Jermann (1998) and Boldrin, Christiano and Fisher (1999) and

\footnotetext{
${ }^{8}$ Assuming that households supply a constant amount of labor amounts to assuming that households incur no dis-utility from working, which is the case for our representative agent.

${ }^{9}$ See, for example, Campbell (1994), who considers permanent and transitory, Cooley and Prescott (1995), transitory, Jermann (1998), permanent and transitory, Prescott (1986), permanent, Rouwenhorst (1995), permanent and transitory.
} 
specify:

$$
\phi\left(I_{t} / K_{t}\right)=\frac{\alpha_{1}}{1-1 / \xi}\left(\frac{I_{t}}{K_{t}}\right)^{(1-1 / \xi)}+\alpha_{2},
$$

where $\alpha_{1}, \alpha_{2}$ are constants and $\alpha_{1}>0 .{ }^{10}$ The parameter $\xi$ is the elasticity of the investmentcapital ratio with respect to Tobin's $q$. If $\xi=\infty$ the capital accumulation equation reduces to the standard growth model accumulation equation without capital adjustment costs.

Each period the firm's output, $Y_{t}$, can be used for either consumption or investment. Investment increases the firm's capital stock, which in turn increases future output. High investment, however, means the agent must forego some consumption today, as can been from the accounting identity $C_{t}=Y_{t}-I_{t}$.

The Return on Investment and the Firm's Problem. Let $\Pi\left(K_{t}, Z_{t} ; W_{t}\right)$ be the operating profit function of the firm, where $W_{t}$ are equilibrium wages. ${ }^{11}$ Firm dividends, $D_{t}$, equal operating profits minus investment:

$$
D_{t}=\Pi\left(K_{t}, Z_{t} ; W_{t}\right)-I_{t}
$$

The firm maximizes firm value. Let $M_{t, t+1}$ denote the stochastic discount factor. The firm's problem is then:

$$
\max _{\left\{I_{t}, K_{t+1}, H_{t}\right\}_{t=0}^{T}} E_{0} \sum_{t=0}^{T} M_{0, t} D_{t},
$$

where $E_{t}$ denotes the expectation operator conditioning on information available up to time $t$. In the appendix, we demonstrate that the return on investment can be written as:

$$
R_{t+1}^{I}=\phi^{\prime}\left(\frac{I_{t}}{K_{t}}\right)\left(\Pi_{K}\left(K_{t+1}, Z_{t+1} ; W_{t+1}\right)+\frac{1-\delta+\phi\left(\frac{I_{t+1}}{K_{t+1}}\right)}{\phi^{\prime}\left(\frac{I_{t+1}}{K_{t+1}}\right)}-\frac{I_{t+1}}{K_{t+1}}\right)
$$

This return to the firm's investment is equivalent to the firm's equity return in equilibrium, $R_{t+1}^{E} \equiv \frac{D_{t+1}+P_{t+1}}{P_{t}}$, where $P_{t}$ denotes the net present value of a claim on all future dividends (see, e.g., Restoy and Rockinger, 1994, and Zhang, 2005).

\footnotetext{
${ }^{10}$ In particular, we set $\alpha_{1}=(\exp (\mu)-1+\delta)^{1 / \xi}$ and $\alpha_{2}=\frac{1}{\xi-1}(1-\delta-\exp (\mu))$. It is straightforward to verify that $\phi\left(\frac{I_{t}}{K_{t}}\right)>0$ and $\phi^{\prime \prime}\left(\frac{I_{t}}{K_{t}}\right)<0$ for $\xi>0$ and $\frac{I_{t}}{K_{t}}>0$. Furthermore, $\phi\left(\frac{I}{K}\right)=\frac{I}{K}$ and $\phi^{\prime}\left(\frac{I}{K}\right)=1$, where $\frac{I}{K}=(\exp (\mu)-1+\delta)$ is the steady state investment-capital ratio.

${ }^{11}$ Wages are in the first part of the paper assumed to be the marginal productivity of labor: $W_{t}=$ $(1-\alpha) Y_{t}$. Since $C_{t}=D_{t}+W_{t}$, we have in this case that $D_{t}=\alpha Y_{t}-I_{t}$.
} 


\section{Results}

The model generates macroeconomic time series such as output, investment, and consumption, as well as aggregate asset prices. In the first part of our analysis, we present a baseline calibration of the model compared to calibrations based on power utility preferences. This illustrates how endogenous long-run risk can improve the ability of the standard productionbased model to jointly explain macroeconomic time series and asset prices and motivates the subsequent analysis of the mechanisms within the model that generate long-run risk. We then investigate the model's implications for both macroeconomic time series and asset prices more generally. Our discussion is centered around different values of the elasticity of intertemporal substitution and the two specifications of technology (permanent vs. transitory). We solve the model numerically by means of the value function iteration algorithm. Please refer to the appendix for a detailed discussion of our solution technique.

\subsection{Calibration}

We report calibrated values of model parameters that are constant across models in Table 1. The capital share $(\alpha)$, the depreciation rate $(\delta)$, the mean technology growth rate $(\mu)$, and the persistence of the transitory technology shocks $(\varphi)$, are set to standard values for quarterly parameterizations (see, e.g., Boldrin, Christiano and Fisher, 2001). We set the coefficient of relative risk aversion $(\gamma)$ to 5 and the capital adjustment costs $(\xi)$, which denotes the elasticity of the investment to capital ratio with respect to Tobin's $q$, to 22 across all models. The former is in the middle of the range of reasonable coefficients of relative risk aversion, as suggested by Mehra and Prescott (1985), while the latter implies only moderate capital adjustment costs. We choose this level of capital adjustment costs to match the macroeconomic moments with our Baseline Model. We vary the elasticity of intertemporal substitution $(\psi)$, the rate of time-discounting preference $(\beta)$, and also the volatility of shocks to technology $\left(\sigma_{z}\right)$, across models. We will discuss the choice of specific parameter values for these variables as we go along.

\subsection{Results from the Baseline Model}

Table 2 shows the Baseline calibration of our model. Panel A shows the moments the model is calibrated to match. Technology shocks are permanent, and the volatility of technology shocks $\left(\sigma_{z}\right)$ is calibrated to match the volatility of output. The time preference parameter $(\beta)$ 


\section{Table 1}

\section{Calibration}

Table 1: Calibrated values of parameters that are constant across models.

\begin{tabular}{clc}
\hline \hline & \multicolumn{2}{c}{ Quarterly Model Calibration } \\
\hline Parameter & \multicolumn{1}{c}{ Description } & Value \\
\hline$\alpha$ & Elasticity of capital & 0.34 \\
$\delta$ & Depreciation rate of capital & 0.021 \\
$\gamma$ & Coefficient of relative risk aversion & 5 \\
$\mu$ & Mean technology growth rate & $0.4 \%$ \\
$\varphi$ & Persistence of AR(1) technology & 0.90 \\
\hline
\end{tabular}

is set to 0.998 in order to match the level of the risk-free rate, the elasticity of intertemporal substitution $(\psi)$ is set to 1.5 to match the volatility of consumption growth, while the risk aversion $(\gamma)$ is set to 5 to match the Sharpe ratio of equity returns. The model matches all of these moments simultaneously, which is a significant achievement for this class of models. As highlighted by, amongst others, Rouwenhorst (1995), Jermann (1998), and Boldrin, Christiano and Fisher (2001), the standard production economy model with power utility preferences cannot jointly explain the dynamic behavior of macroeconomic variables and asset prices. ${ }^{12}$ For comparison, Table 2 also shows two calibrations of the power utility model, which restricts $\gamma=\frac{1}{\psi}$. In Power Utility Model I, we use the same EIS parameter, $\psi=$ 1.5 , which implies $\gamma=2 / 3$. This model can match the volatility of output and consumption, but generates a Sharpe ratio that is an order of magnitude too low compared to the empirical value. Power Utility Model II uses the same coefficient of relative risk aversion as in the Baseline Model, which implies $\psi=1 / 5$. The low EIS leads to a too high level of the riskfree rate. The Sharpe ratio is now 0.26 versus 0.33 in the data. However, the higher Sharpe ratio is achieved with a consumption growth volatility that is twice as high as both in the data and in the Baseline Model. So why is it that the Baseline model yields a higher Sharpe ratio with the same coefficient of risk aversion and only half the consumption volatility? When $\gamma>\frac{1}{\psi}$, consumers have a preference for early resolution of uncertainty, which creates a role for long-run risk (see appendix). The dynamic behavior of the optimal, endogenous consumption choice gives rise to such long-run consumption risk, which is the reason the equity Sharpe ratio is higher in the Baseline Model although the volatility of consumption

\footnotetext{
${ }^{12}$ Boldrin, Christiano, Fisher (2001): '[RBC models] have been notoriously unsuccessful in accounting for the joint behavior of asset prices and consumption.'. See also Cochrane (2005).
} 


\section{Table 2}

\section{Asset Pricing Moments: Adjusted Model versus a Standard Model}

Table 2: This table reports annual asset pricing moments for two calibrations of the standard stochastic growth model where the representative agent has power utility preferences, as well as the Baseline Model presented in this paper. All models have permanent technology shocks. The parameters are the same across the models $(\beta=0.998$ and $\xi=22)$, except the coefficient of relative risk aversion $(\gamma)$ and the elasticity of intertemporal substitution $(\psi)$. The volatility of shocks to technology, $\sigma_{z}$, is calibrated so that the models fit the volatility of output growth. The equity returns in both models are for an unlevered claim on the endogenous, aggregate dividends. The equity premium due to short-run risk is defined as $\gamma \operatorname{cov}\left(\Delta c_{t}, R_{t}^{E}-R_{f, t}\right)$.

\begin{tabular}{|c|c|c|c|c|}
\hline Statistic & $\begin{array}{c}\text { U.S. Data } \\
1929-1998\end{array}$ & $\begin{array}{l}\text { Power Utility } \\
\quad \text { Model I } \\
\psi=1.5, \gamma=\frac{1}{1.5}\end{array}$ & $\begin{array}{l}\text { Power Utility } \\
\quad \text { Model II } \\
\psi=\frac{1}{5}, \gamma=5\end{array}$ & $\begin{array}{c}\text { Baseline } \\
\text { Model } \\
\psi=1.5, \gamma=5\end{array}$ \\
\hline \multicolumn{5}{|c|}{ Panel A - Matched Moments } \\
\hline $\begin{array}{l}\text { Volatility of Consumption Gro } \\
\sigma[\Delta c](\%)\end{array}$ & wth & 2.72 & 5.48 & 2.72 \\
\hline $\begin{array}{l}\text { Relative Volatility of Consump } \\
\sigma[\Delta c] / \sigma[\Delta y]\end{array}$ & $\begin{array}{l}\text { ption and Output } \\
0.52\end{array}$ & $D P)$ & 1.05 & 0.52 \\
\hline $\begin{array}{l}\text { Level of Risk-free Rate } \\
E\left[R_{f}\right](\%)\end{array}$ & 0.86 & 1.83 & 5.07 & 0.86 \\
\hline $\begin{array}{l}\text { Sharpe ratio of Equity Return } \\
E\left[R^{E}-R_{f}\right] / \sigma\left[R^{E}-R_{f}\right]\end{array}$ & 0.33 & 0.02 & 0.26 & 0.33 \\
\hline \multicolumn{5}{|l|}{ Panel B - Other Moments } \\
\hline $\begin{array}{l}\text { Volatility of the Risk-free Rate } \\
\sigma\left[R_{f}\right](\%)\end{array}$ & 0.97 & 0.45 & 1.00 & 0.43 \\
\hline $\begin{array}{l}\text { Equity Returns } \\
E\left[R^{E}-R_{f}\right](\%) \\
\sigma\left[R^{E}-R_{f}\right](\%)\end{array}$ & $\begin{array}{r}6.33 \\
19.42\end{array}$ & $\begin{array}{l}0.01 \\
0.61\end{array}$ & $\begin{array}{l}0.10 \\
0.38\end{array}$ & $\begin{array}{l}0.19 \\
0.57\end{array}$ \\
\hline Decomposing the Equity Prem & $\begin{array}{l}\text { ium }(\%) \\
\text { Short-Run Risk } \\
\text { Long-Run Risk }\end{array}$ & $\begin{array}{l}0.01(100 \%) \\
0.00(0 \%)\end{array}$ & $\begin{array}{l}0.10(100 \%) \\
0.00(\quad 0 \%)\end{array}$ & $\begin{array}{l}0.07(39 \%) \\
0.12(61 \%)\end{array}$ \\
\hline
\end{tabular}


growth is lower.

Panel B shows financial moments the Baseline Model was not calibrated to fit. The riskfree rate has low volatility, as in the data, despite the high price of risk. This feature is an important improvement over production economy models with habit preferences, which can match the high price of risk, but generate much too volatile risk-free rates (see, e.g., Jermann, 1998, and Boldrin, Christiano and Fisher, 2001). Since the reciprocal of the risk-free rate is the conditional expectation of the stochastic discount factor, mismatching the risk-free rate volatility implies that the dynamic behavior of the stochastic discount factor is also mismatched. The equity claim is defined as the (unlevered) claim to aggregate dividends. The equity return volatility is quite low in all the models, but the equity premium in the Baseline Model is more than an order of magnitude higher than for Power Utility Model I and twice as high as for Power Utility Model II. As was the case for the Sharpe ratio, this is both due to a higher coefficient of relative risk aversion and the presence of long-run risk. In fact, Panel B reports that $61 \%$ of the risk premium in the Baseline Model is due to long-run risk, where short-run risk is defined as $\gamma \times \operatorname{cov}\left(R_{t}^{E}-R_{f, t}, \Delta c_{t}\right)$.

At $0.19 \%$ per year, however, the equity premium is still more than an order of magnitude too low compared to historical values. This is typical for production economies, as the equity claim is not volatile enough. One standard remedy for this problem is to assume a stochastic depreciation rate (see, e.g., Storesletten, Telmer, and Yaron, 2005, and Gomes and Michaelides, 2005). In Section 4.4.4, we propose an alternative remedy. We show that if we calibrate the wage process to the data, the ensuing dividend process is also closer to the data. As a result, the risk premium increases by an order of magnitude to levels close to historical values.

In the following, we provide intuition for how endogenous long-run risk arises in the model, and how it affects asset prices and macroeconomic moments, and, in particular, the dynamic behavior of consumption.

\subsection{The Endogenous Consumption Choice and The Price of Risk}

Before we report moments from different calibrations of the model, it is useful to provide general intuition for the endogenous consumption choice and how it is related to the persistence of the technology shocks and the price of risk in the economy. From the stochastic discount factor (see eq. (2)), we can see that there are two sources of risk in this economy. The first is the shock to realized consumption growth, which is the usual risk factor in the Consumption 
CAPM. The second risk factor is the shock to the return on total wealth. Total wealth is the sum of human and financial capital, and the dividend to total wealth is consumption. Assume for the moment that future expected consumption growth and returns are constant. Total wealth, $A_{t}$, is then given by:

$$
A_{t}=\frac{C_{t}}{r_{a}-g_{c}}
$$

where $r_{a}$ is the expected return to wealth and $g_{c}$ is expected consumption growth: Total wealth is a function of both current and future expected consumption. Therefore, shocks to both realized and expected consumption growth translate into shocks to the realized return to wealth. This example illustrates how we can think of shocks to expected consumption growth as the second risk factor instead of the return to wealth. ${ }^{13}$ Understanding the dynamic behavior of consumption growth is thus necessary in order to understand the asset pricing properties of the production economy model with Epstein-Zin preferences. In the following, we consider the consumption response to both transitory and permanent technology shocks. ${ }^{14}$

Transitory Technology Shocks. Panel A of Figure 1 shows the impulse-response functions of technology and consumption to a transitory technology shock. Agents in this economy want to take advantage of the temporary increase in the productivity of capital due to the temporarily high level of technology. To do so, they invest immediately in capital at the expense of current consumption. As a result, the consumption response is hump-shaped. This figure illustrates how time-varying expected consumption growth arises endogenously in the production economy model: A positive shock to realized consumption growth (the initial consumption response) is associated with positive short-run expected consumption growth, but negative long-run expected consumption growth as consumption reverts back to the steady state. Thus, the shock to long-run expected consumption growth has the opposite sign of the shock to realized consumption growth, implying that shocks to realized consumption growth are hedged by shocks to the expected long-run consumption growth rate.

\footnotetext{
${ }^{13}$ Following Bansal and Yaron (2004), we explicitly show this in the appendix through a log-linear approximation of the return to wealth.

${ }^{14}$ We make a strong distinction between transitory and permanent shocks in this section to provide clear intuition. As $\varphi \rightarrow 1$, the transitory shock specification (5) approaches the permanent shock specification (4). The dynamics of the model are in that case very similar for both specifications, so there is actually no discontinuity at $\varphi=1$ in terms of the model's asset pricing implications. However, the transitory shocks need to be extremely persistent for the transitory and permanent cases to be similar. At $\varphi=0.9$, which is the case we consider in our calibration, the dynamic behavior of the model with permanent shocks is very different from the model with transitory shocks. The reader could therefore think of "transitory vs. permanent" shocks as "not extremely persistent vs. extremely persistent" shocks.
} 
Figure 1 - Transitory and Permanent Shocks

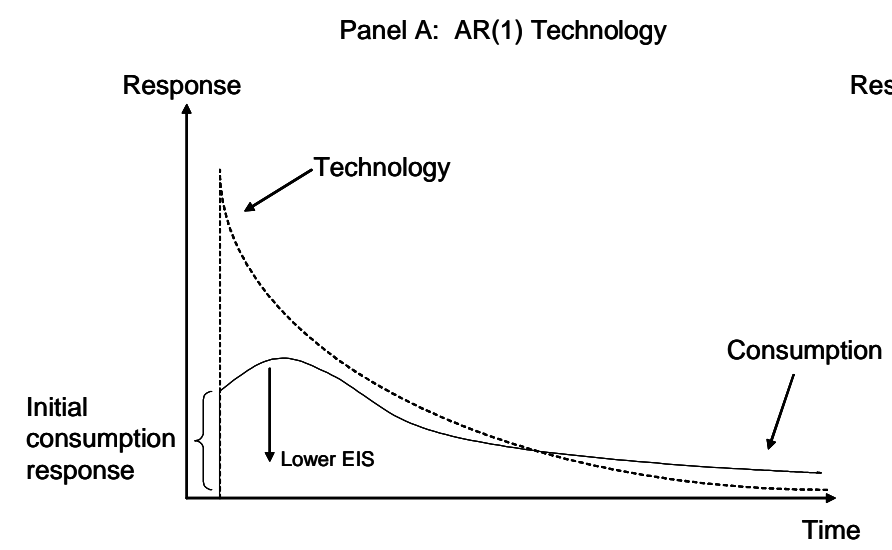

Panel B: Random Walk Technology

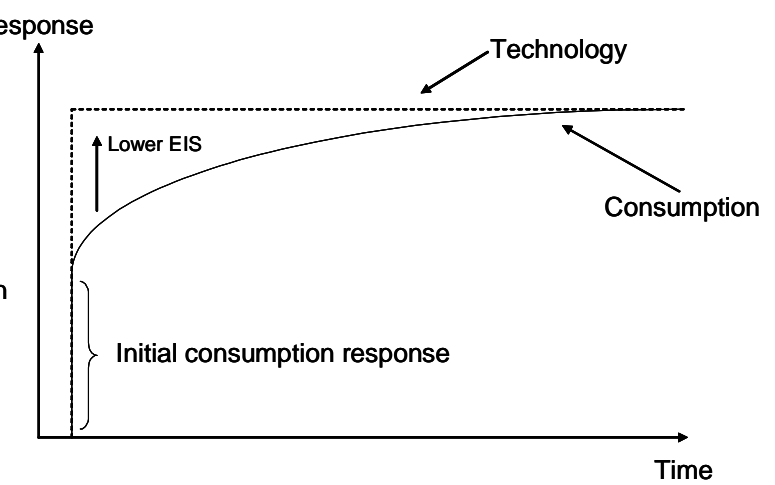

Figure 1: Impulse-Responses for Technology and Consumption. Panel A shows the impulseresponse of technology and consumption to a transitory technology shock. Panel B shows the impulse-response of technology and consumption to a permanent technology shock. The arrows show the direction in which the optimal consumption response changes if the desire for a smoother consumption path increases (i.e., the elasticity of intertemporal substitution decreases).

As a consequence, long-run risk decreases the price of risk in the economy with transitory technology shocks.

Permanent Technology Shocks. With permanent technology shocks, long-run consumption risk has the opposite effect. Panel B of Figure 1 shows the impulse-response functions of technology and consumption to a permanent technology shock. Technology adjusts immediately to the new steady state, and the permanently higher productivity of capital implies that the optimal long-run levels of both capital and consumption are also higher. Agents invest immediately in order to build up capital at the expense of current consumption, and consumption gradually increases towards the new steady state after the initial shock. Thus, a positive shock to realized consumption growth (the initial consumption response) is associated with positive long-run expected consumption growth. In this case, long-run risk increases the price of risk in the economy because a positive technology shock induces positive shocks to both realized consumption growth and long-run expected consumption growth.

The Elasticity of Intertemporal Substitution. The elasticity of intertemporal substitution $(E I S)$ is an important determinant of the dynamic behavior of consumption growth. A low EIS translates into a strong desire for intertemporally smooth consumption paths. 
In other words, agents strive to minimize the difference between their level of consumption today (after the shock) and future expected consumption levels. The arrows in Figure 1 indicate the directions in which the initial optimal consumption responses change if the desire for a smoother consumption path increases. As the elasticity of intertemporal substitution decreases, agents desire a "flatter" response curve. From the figure, we can conjecture that a lower EIS decreases the volatility of expected future consumption growth. A high EIS, on the other hand, implies a higher willingness to substitute consumption today for higher future consumption levels. Therefore, the higher the EIS, the higher the volatility of expected consumption growth and the higher the levels of long-run risk in the economy. A high EIS thus decreases the price of risk if technology shocks are transitory, but increases the price of risk if technology shocks are permanent.

Capital Adjustment Costs. Capital adjustment costs $(C A C)$ make it more costly for firms to adjust investment. Therefore, higher $C A C$ induce lower investment volatility. We can therefore use $C A C$ to, as far as possible, match the empirical relative volatilities of consumption, investment, and output with each model.

\subsubsection{Results from Calibrated Models}

We confirm the intuition from the impulse-responses in Figure 1 by reporting relevant macroeconomic moments and the equilibrium price of risk for different model calibrations. In particular, Table 3 reports relevant macroeconomic moments and consumption dynamics for models with either transitory or permanent technology shocks and different levels of the elasticity of intertemporal substitution $(\psi=1 / \gamma, 0.5,1.5)$. We match the U.S. output volatility over the period 1929 to 1998 with all models by setting the volatility of the technology shocks, $\sigma_{\varepsilon}$, appropriately. We re-calibrate the discount factor $(\beta)$ for each model so as to jointly match the values for $(C / Y),(I / Y),(D / Y)$, that is aggregate average consumption, investment, and dividends relative to output, with each model. This is quite important, both since these are first-order moments and because we compare the volatility of growth rates across models. Capital adjustment $\operatorname{costs}(\xi)$ are the same across models and the value of $\xi$ is set in order to match the relative volatility of consumption to output with the Baseline Model. The coefficient of relative risk aversion $(\gamma)$ is constant across models. We show in the appendix, confirming Tallarini (2000), that the level of $\gamma$ has only second-order effects on the time series behavior of the macroeconomic variables. 


\section{Table 3}

\section{Macroeconomic Moments and Consumption Dynamics}

Table 3: This table reports relevant macroeconomic moments and consumption dynamics for models with either transitory $(\varphi=0.90)$ or permanent technology shocks and different levels of the elasticity of intertemporal substitution $(\psi)$. The coefficient of relative risk aversion $(\gamma)$ is 5 across all models. We re-calibrate the discount factor $(\beta)$ for Models 1 to 5 so as to jointly match the values for $(\mathrm{C} / \mathrm{Y})$, $(\mathrm{I} / \mathrm{Y}),(\mathrm{D} / \mathrm{Y})$, with each model. In the Baseline Model, $\beta=0.998$, allowing the model to match the level of the risk-free rate. Capital adjustment costs $(\xi)$ are 22 in order to match the relative volatility of consumption to output with the Baseline Model. We estimate the following process for the consumption dynamics: $\Delta c_{t+1}=\mu+x_{t}+\eta_{t+1}, x_{t+1}=\rho x_{t}+e_{t+1} . \Delta x=\log \left(X_{t}\right)-\log \left(X_{t-1}\right)$, and $\sigma[X]$ denotes the standard deviation of variable $X$. We use annual U.S. data from 1929 to 1998 from the Bureau of Economic Analysis. The sample is the same as in Bansal and Yaron (2004).

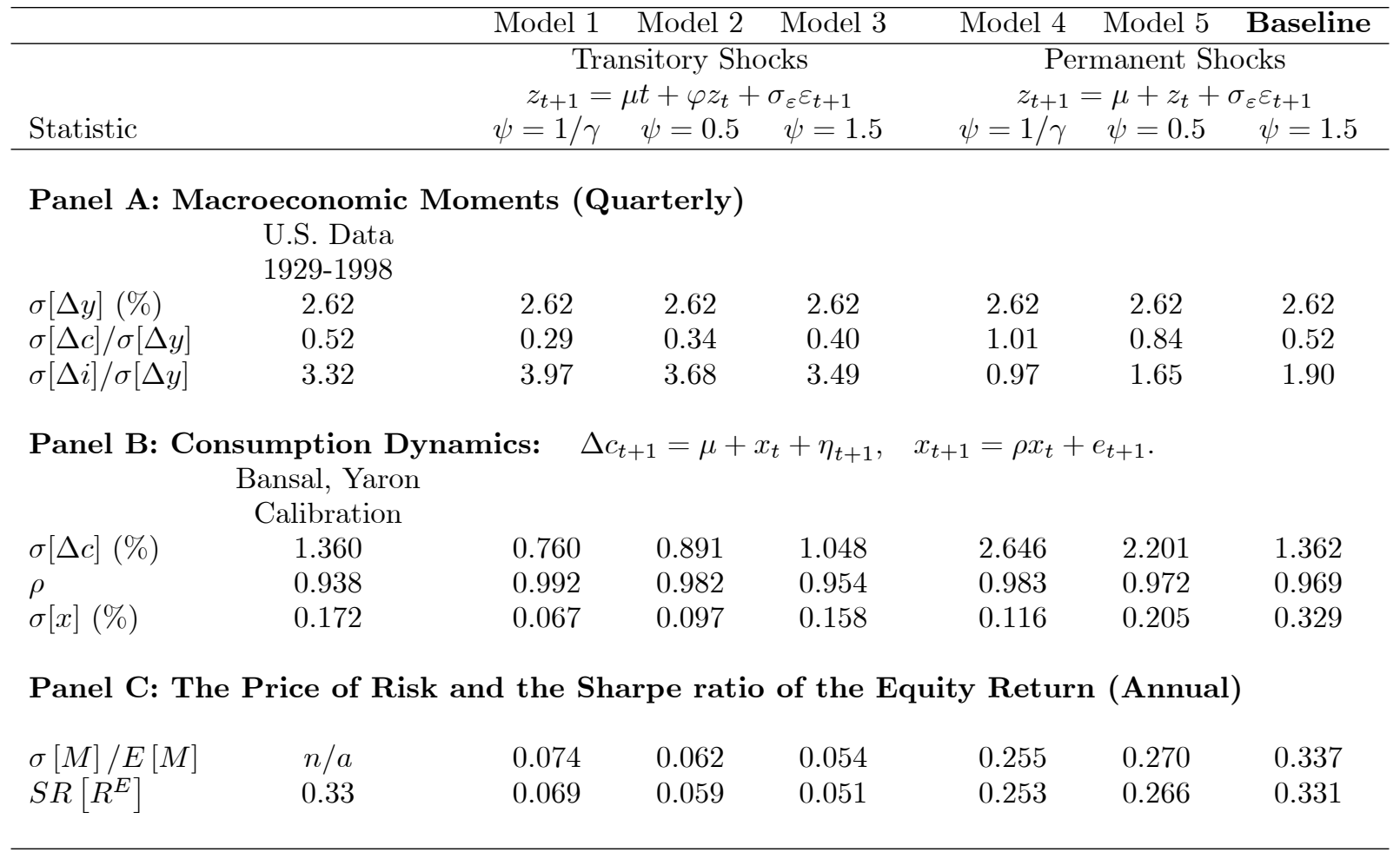


The Volatility of Realized Consumption Growth. The volatility of realized consumption growth is the standard risk factor in consumption-based asset pricing models, where a higher volatility of consumption growth leads to a higher price of risk. This is not necessarily true in this model.

In Models 1 to 3, technology shocks are transitory and the EIS is increasing across models from the power utility case $(\psi=1 / \gamma=0.2$, Model 1) to 1.5 (Model 3). Panel A of Table 3 shows that consumption volatility is increasing with EIS. Agents with higher EIS take advantage of a temporarily high technology level by consuming relatively more today and less in the future as technology reverts back to its long-run trend. As a result, the level of risk associated with shocks to realized consumption growth is increasing with the EIS in the model with transitory shocks. The overall price of risk in the economy, however, is decreasing in the EIS (Panel C in Table 3), due to long-run risks.

In Models 4,5, and the Baseline Model, technology shocks are permanent. Here the consumption growth volatility is decreasing with the EIS. Consider a positive shock to technology. Since the shock is permanent, agents with a high EIS want to increase the capital stock to its new optimal level as quickly as possible for consumption to grow faster towards its new, permanently higher level. To that end they need to invest more today, implying a smaller initial consumption response. Thus, the level of risk associated with shocks to realized consumption growth is decreasing with the EIS in the model with permanent shocks. With respect to this standard risk factor, a higher EIS therefore reduces risk in the permanent shock model. Nevertheless, Panel $\mathrm{C}$ of Table 3 shows that the price of risk in this case is, again, due to long-run risks increasing in the EIS.

Thus, the models imply a surprising inverse relation between the volatility of realized consumption growth and the price of risk. The magnitude of this relation is large. In the transitory shock models, the relative consumption volatility increases by $40 \%$ from Model 1 to Model 3, while the price of risk decreases by $30 \%$. In the permanent shock models, the relative consumption volatility decreases by $50 \%$ from Model 4 to the Baseline Model, while the price of risk increases by $30 \%$.

The Volatility of Expected Consumption Growth (Long-run Risk). The above results are due to the varying degree and effect of long-run risk in the models because shocks to expected consumption growth are also a risk factor. In Panel B of Table 3, we report both the volatility of consumption growth, the volatility of conditional expected consumption growth $\left(x_{t}\right)$, and the latter's first order autocorrelation $(\rho)$. To a first order, these statistics 
summarize the magnitude and nature of long-run risk in the models. ${ }^{15}$ The implied system for consumption growth is:

$$
\begin{aligned}
\Delta c_{t+1} & =\mu+x_{t}+\eta_{t+1}, \\
x_{t+1} & =\rho x_{t}+e_{t+1}, \\
E_{t}\left[\eta_{t+1}\right] & =E_{t}\left[e_{t+1}\right]=0,
\end{aligned}
$$

which is similar to that assumed in the exchange economy of Bansal and Yaron (2004). For comparison, Panel B also gives the parameters that Bansal and Yaron use in their calibration. The relative magnitudes of the volatility of realized and expected consumption growth show that the time-varying growth component is very small. The implied average $R^{2}$ across models is around $1-2 \%$. Note however that the persistence of the expected consumption growth rate $(\rho)$ is very high, which is important if risk associated with a small time-varying expected consumption growth rate component is to have quantitatively interesting asset pricing implications. As expected from the discussion in Section 4, the volatility of expected consumption growth, $\sigma[x]$, is increasing in the elasticity of intertemporal substitution. Whether shocks to expected consumption growth increase or decrease the price of risk in the economy, however, depends on their effect on the return to total wealth and its correlation with realized consumption growth. The negative correlation between shocks to realized and expected consumption growth induced by transitory technology shocks yields a price of risk that is decreasing in the amount of long-run risk. For permanent technology shocks, this correlation is positive and the price of risk in the economy is increasing in the amount of long-run risk.

\subsection{Asset Pricing Implications}

Table 4 presents key financial moments. We calibrate the volatility of aggregate consumption growth to its empirical value for each model we report in Table 4 by adjusting the volatility of technology growth. Keeping the volatility of aggregate consumption growth constant across models allows us to compare asset prices while holding this traditional measure of risk constant. This approach highlights the impact of long-run risk, with the caveat that

\footnotetext{
${ }^{15}$ In the appendix, we show that these moments indeed capture most of the dynamics of consumption growth generated by the models and as such are meaningful moments to consider. There is some heteroskedasticity in both shocks to expected and realized consumption growth, but these effects are second order.
} 


\section{Table 4}

\section{Financial Moments}

Table 4: This table reports relevant financial moments and consumption dynamics for models with either transitory $(\varphi=0.90)$ or permanent technology shocks and different levels of the elasticity of intertemporal substitution $(\psi)$. The coefficient of relative risk aversion $(\gamma)$ is 5 across all models, while the discount factor $(\beta)$ is 0.998 and capital adjustment costs $(\xi)$ are 22 , in order to match the equity Sharpe ratio, the level of the risk-free rate, and the relative volatility of consumption to output with the Baseline Model. We re-calibrate $\sigma_{\varepsilon}$ in order to match the volatility of consumption growth with each model. We estimate the following process for the consumption dynamics: $\Delta c_{t+1}=$ $\mu+x_{t}+\sigma_{\eta} \eta_{t+1}, x_{t+1}=\rho x_{t}+\sigma_{e} e_{t+1} . \sigma[X]$ denotes the standard deviation of variable $X$. The data are taken from Bansal and Yaron (2004) who use annual U.S. data from 1929 to 1998.

\begin{tabular}{|c|c|c|c|c|c|c|}
\hline & & Model 7 & Model 9 & Model 10 & Model 11 & Baseline \\
\hline & & \multicolumn{2}{|c|}{ Transitory Shocks } & \multicolumn{3}{|c|}{ Permanent Shocks } \\
\hline Statistic & Data & $\begin{array}{c}z_{t+1}=\mu t+\varphi z_{t} \\
\psi=1 / \gamma \quad \psi=0.5\end{array}$ & $\begin{array}{l}\sigma_{\varepsilon} \varepsilon_{t+1} \\
\psi=1.5\end{array}$ & $\begin{aligned} & z_{t+1} \\
\psi= & 1 / \gamma\end{aligned}$ & $\begin{aligned}= & \mu+z_{t}+ \\
& \psi=0.5\end{aligned}$ & $\begin{array}{l}\varepsilon^{\varepsilon} \varepsilon_{t+1} \\
\quad \psi=1.5\end{array}$ \\
\hline
\end{tabular}

Panel A: The Price of Risk and Consumption Dynamics (Annual)

$\begin{array}{llllllll}\sigma[\Delta c](\%) & 2.72 & 2.72 & 2.72 & 2.72 & 2.72 & 2.72 & 2.72 \\ \sigma[x](\%) & n / a & 0.12 & 0.14 & 0.19 & 0.06 & 0.10 & 0.33 \\ & & & & & & & \\ \sigma[M] / E[M] & n / a & 0.13 & 0.08 & 0.02 & 0.13 & 0.18 & 0.34 \\ S R\left[R^{A}\right] & n / a & 0.12 & 0.08 & 0.02 & 0.13 & 0.17 & 0.34 \\ S R\left[R^{E}\right] & 0.33 & 0.11 & 0.08 & 0.02 & 0.13 & 0.17 & 0.33\end{array}$

Panel B: Financial Moments (Annual)

$\begin{array}{llllllll}E\left[R_{f}\right](\%) & 0.86 & 7.63 & 3.70 & 1.80 & 7.68 & 3.45 & 0.86 \\ \sigma\left[R_{f}\right](\%) & 0.97 & 1.14 & 0.56 & 0.25 & 0.58 & 0.41 & 0.43\end{array}$

The Consumption Claim

$\begin{array}{llllllll}E\left[R^{A}-R_{f}\right](\%) & n / a & 0.78 & 0.36 & 0.05 & 0.03 & 0.19 & 1.46\end{array}$

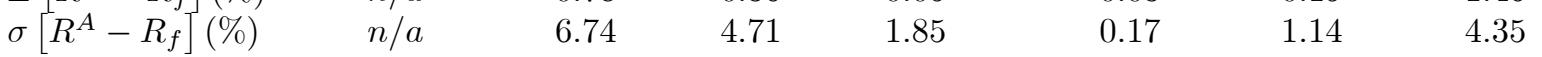

The Dividend Claim

$\begin{array}{lrrrrrrr}E\left[R^{E}-R_{f}\right](\%) & 6.33 & 0.25 & 0.13 & 0.03 & 0.04 & 0.05 & 0.19 \\ \sigma\left[R^{E}-R_{f}\right](\%) & 19.42 & 2.37 & 1.78 & 1.29 & 0.22 & 0.28 & 0.58\end{array}$


the volatility of output $\left(Y_{t}\right)$ is mismatched for all models but the Baseline Model. We use the coefficient of relative risk aversion $(\gamma)$, the discount factor $(\beta)$, and adjustment costs $(\xi)$ to respectively match the equity Sharpe ratio, the level of the risk-free rate, as well as the relative volatility of consumption to output with the Baseline Model, which is the model that best fits the macroeconomic moments. We keep these parameters $(\gamma, \beta, \xi)$ constant across models in order to examine the effect of the EIS and technology specification on endogenous long-run risk and asset prices. The empirical moments are taken from Bansal and Yaron (2004), who use annual U.S. data from 1929 to 1998.

\subsubsection{The Price of Risk and Sharpe Ratios}

Panel A of Table 4 reconfirms that long-run risk, as measured by the volatility of the expected consumption growth rate, $\sigma[x]$, increases substantially for both the case of permanent and transitory shocks as we increase the $E I S$, and that the price of risk $(\sigma[M] / E[M])$, as well as the Sharpe ratio of the return on wealth and the return on equity, are decreasing with the EIS for transitory shocks and increasing with the EIS for permanent shocks. In the case of transitory shocks, the Sharpe ratio of equity returns drops more than five-fold from 0.11 to 0.02 as the $E I S$ increases from $0.2(=1 / \gamma)$ to 1.5 . In the case of permanent shocks, the Sharpe ratio of equity returns increases from 0.13 to 0.33 as the EIS increases from 0.2 to 1.5. Comparing Model 10 (power utility) with the Baseline Model $\left(\gamma>\frac{1}{\psi}\right)$, endogenous long-run risk combined with a preference for early resolution of uncertainty almost triples the price of risk in the economy.

\subsubsection{The Risk-free Rate}

Panel B of Table 4 shows that the risk-free rate is decreasing in the EIS, as expected. A higher EIS increases the intertemporal substitution effect (see eq. (40)), and the volatility of the risk-free rate is low. The time-variation in expected consumption growth rates does not induce too volatile risk-free rates, because the growth shocks are very persistent and not very volatile. This is an improvement over habit formation models like in Jermann (1998) or Boldrin, Christiano and Fisher (2001), where time-variation in the state variable "surplus consumption" induces much too volatile risk-free rates when the models are calibrated to match empirical proxies for the price of risk (e.g., the equity Sharpe ratio).

Since the risk-free rate is the reciprocal of the conditional expected value of the stochastic discount factor, a misspecified risk-free rate implies a misspecified stochastic discount factor. 
Therefore, it is important to note that the production economy model we consider in this paper, in conjunction with permanent technology shocks, can match both the level and volatility of the risk-free rate, as well as empirical measures of the price of risk.

\subsubsection{The Level and the Volatility of Excess Returns}

For the models with permanent shocks, the average excess returns on both total wealth and equities are strongly increasing in the EIS (Panel B of Table 4). From the power utility model with $\gamma=5, \psi=\frac{1}{\gamma}$ to the case with $\gamma=5, \psi=1.5$ the equity premium increases six-fold from $0.04 \%$ to $0.19 \%$, and equity return volatility increases from $0.22 \%$ to $0.58 \%$. While these are substantial relative increases, the equity premium is still roughly an order of magnitude too low due to the low volatility of equity returns. Note, however, that the premium and volatility of returns to the wealth portfolio are much more sensitive to increases in the EIS. The return premium on the consumption claim increases almost two orders of magnitude, from $0.03 \%$ to $1.46 \% .^{16}$

The production economy model generates dividends endogenously and the endogenous dividend process differs from the endogenous consumption process along important dimensions: While equity dividends are given by $D_{t}^{E}=\alpha Y_{t}-I_{t}$, dividends to the wealth portfolio are given by $D_{t}^{A}=C_{t}=Y_{t}-I_{t}$. Consider a permanent, positive shock to technology. If investors have higher $E I S$, this results in higher investment volatility and higher expected future consumption growth. Both equity dividends as well as dividends to the wealth portfolio now respond less to a positive shock. However, equity dividends are much more sensitive to this effect, and may even decrease in response to a shock, implying a negative correlation between dividend growth and expected consumption growth. So, while the price of the equity claim increases, the current dividend decreases, which dampens the total equity return response to technology shocks. The result is that the equity return volatility, and thus the equity premium, increase by less with the EIS relative to the total asset return.

In an exchange economy, it is possible to exploit the fact that the claims to total wealth and equity have different dividend processes (i.e., consumption and dividends), and use this as a degree of freedom to fit the asset pricing moments. Bansal and Yaron (2004), for instance, exogenously specify the dividend process such that expected dividend growth is very

\footnotetext{
${ }^{16}$ Many papers define dividends as a levered claim to the consumption stream, in order to fit the volatility of dividend growth, the high equity return volatility and the equity risk premium. With a leverage factor of about 3 the "equity" return premium for the Baseline Model would be around $4 \%$ with a return volatility of about $12 \%$.
} 
sensitive to shocks to expected consumption growth, which makes the equity claim risky and volatile. That way they are able to fit the equity volatility, and thus the equity premium, with roughly the same (exogenous) consumption process and preference parameters as in the Baseline Model. The production economy model, on the other hand, restricts the joint dynamic behavior of aggregate consumption and dividends. Thus, while the general equilibrium framework considered so far in this paper provides a theoretical justification for a consumption process with long-run risk, it imposes constraints on dividends that are unfavorable in terms of matching the volatility of equity returns. We take a closer look at those constraints in the following section.

\subsubsection{Baseline Model II: Alternative Specification for Wages}

Is the low volatility of the (unlevered) equity claim endemic to the class of models considered in this paper? In this section, we argue that a promising avenue for future research is to carefully consider the mechanisms for labor supply and wages. So far, we have considered an economy where agents supply a constant amount of labor and where wages are set such that it is optimal for the firm to demand exactly the same amount of labor: wages equal the marginal product of labor. The equilibrium total wages paid are then $W_{t}=(1-\alpha) Y_{t}$ (see appendix). Thus, log wage growth is perfectly correlated with and as volatile as log output growth. In the data, however, wages are only about half as volatile as output and not strongly procyclical. In this section, we specify the wage process to match the empirical volatility of wages relative to the volatility of output and show that this wage process, which is closer to what we observe in the data, allows the model to also generate a process for dividends that is much closer to the data. As a result, the equity premium increases by an order of magnitude.

In the recent labor market search literature, less volatile and less procyclical wages have been identified as an important avenue for making operating profits, firm value, and ultimately employment more volatile and more procyclical. ${ }^{17}$ We essentially propose the same in order to resolve the equity premium puzzle in our model. Instead of assuming that labor is paid its marginal product, we calibrate the wage process to the data. In the presence of

\footnotetext{
${ }^{17}$ In that literature, the counterfactually low volatility of employment, induced by too low volatility of firm values, has been a long-standing puzzle, dubbed the "Shimer puzzle". For accounts of (and solutions for) the lack of movement in employment within the standard Mortensen and Pissarides (1994) labor market matching framework, see for example Den Haan, Ramey, Watson (2000), Hornstein, Krusell, Violante (2005), Shimer (2005), and Den Haan and Kaltenbrunner (2006). Making wages "stickier" has been originally promoted as an important contribution to the resolution of the Shimer puzzle by Hall (2005).
} 
labor market frictions, for instance a search and matching friction, it is not necessarily true that labor is paid its marginal product. The search and matching literature assumes instead that wages are an outcome of a bargaining process between firm and worker. The wage process we propose is similar to the sticky wage rule Hall (2005) proposes. The consequence of less volatile wages are more volatile and more procyclical firm operating profits and firm dividends compared to the original model. This in turn leads to more volatile firm values and equity returns and to a higher equity risk premium. One way of viewing this is that we increase the operating leverage of the firm by introducing a less volatile and less procyclical "fixed-cost-component".

We specify the following wage process:

$$
W_{t}^{a d j}=\omega_{0} Y_{t}^{\omega_{1}} K_{t}^{1-\omega_{1}}
$$

so that wages are a constant fraction of a composite measure of the size of the aggregate economy. Note that $Y_{t}$ fluctuates much more around the trend growth rate than does $K_{t}$. As a result, wages are less volatile the lower $\omega_{1}$, which enables us to fit the relative volatility of wages and output. We calibrate this process to U.S. data from 1952 to $2004 .^{18}$

Table 5 reports asset pricing moments for the Baseline Model. We report both the original equity return, that is the return of a claim on the original dividend process, as well as the adjusted equity return, that is a claim on the new dividend process $\left(D_{t}^{a d j}=Y_{t}-W_{t}^{a d j}-I_{t}\right)$.

From Table 5 we can see that the standard production economy model has the potential to match both the level as well as the volatility of the equity premium. With our simple adjustment of the process for wages, the premium of the unlevered equity return increases from $0.19 \%$ to $1.41 \%$ for the Baseline Model. Because the equity return from the data is the return on a levered equity claim we add financial leverage to our model (the debt is assumed risk-free and specified as in Jermann, 1998). Now the model is able to generate an equity premium of $2.12 \%$ with an equity return volatility of $6.56 \%$. The model underestimates the volatility of dividend growth, but matches the correlation between dividend growth and consumption growth. Given that we calibrate the wage process and not the process for dividends, the model does generate remarkably realistic dividend processes.

We conclude that a wage process closer to what we observe in the data yields an equity

\footnotetext{
${ }^{18}$ We set $\omega_{0}=0.19$ in order to match $E\left[\frac{D}{Y}\right]=13 \%$ and $\omega_{1}=0.63$ in order to match $\frac{\sigma[h p(w)]}{\sigma[h p(y)]}=0.63$, where $h p(x)$ denotes the cyclical component of $x$ extracted using the Hodrick-Prescott filter with a smoothing parameter of 1600 .
} 


\section{Table 5}

\section{Adjusted Wage Process - Asset Pricing Moments}

Table 5: This table reports asset pricing moments for the Baseline Model. The elasticity of intertemporal substitution $(\psi)$ is 1.5 . We report both the original equity return, that is the return of a claim on the original dividend process, as well as the adjusted equity return, that is a claim on the adjusted dividend process. The data are taken from Bansal and Yaron (2004) who use U.S. financial markets data from 1929 to 1998. All values reported in the table are annual.

\begin{tabular}{|c|c|c|}
\hline Statistic & Data & Baseline Model \\
\hline$\sigma[\triangle c](\%)$ & 2.72 & 2.72 \\
\hline$\sigma[\triangle c] / \sigma[\Delta y]$ & 0.52 & 0.52 \\
\hline$\sigma[M] / E[M]$ & $n / a$ & 0.34 \\
\hline$E\left[R_{f}\right](\%)$ & 0.86 & 0.86 \\
\hline$\sigma\left[R_{f}\right](\%)$ & 0.97 & 0.43 \\
\hline$S R\left[R^{E}\right]$ & 0.33 & 0.33 \\
\hline$E\left[R r^{E}-R_{f}\right](\%)$ & 6.33 & 0.19 \\
\hline$\sigma\left[R^{E}-R_{f}\right](\%)$ & 19.42 & 0.57 \\
\hline$S R\left[R^{\text {Eadj }}\right]$ & 0.33 & 0.33 \\
\hline$E\left[R^{E a d j}-R_{f}\right](\%)$ & 6.33 & 1.41 \\
\hline$\sigma\left[R^{E a d j}-R_{f}\right](\%)$ & 19.42 & 4.21 \\
\hline$\sigma\left[\triangle d^{a d j}\right](\%)$ & 5.27 & 0.99 \\
\hline $\operatorname{corr}\left[\triangle d^{\text {adj }}, \triangle c\right]$ & 0.45 & 0.45 \\
\hline \multicolumn{3}{|c|}{ Financial Leverage } \\
\hline & Data: $(D / V \approx 0.33)$ & Model: $D / V=0.33$ \\
\hline$E\left[R^{E a d j}-R_{f}\right](\%)$ & 6.33 & 2.12 \\
\hline$\sigma\left[R^{E a d j}-R_{f}\right](\%)$ & 19.42 & 6.56 \\
\hline
\end{tabular}


risk premium substantially closer to the what we find in the data. An important step for future research is to endogenize labor and hours worked in the framework of this paper. ${ }^{19}$

\subsection{The Case of $\gamma<\frac{1}{\psi}$}

In the previous discussions our focus was on the case of $\gamma>\frac{1}{\psi}$, where agents prefer early resolution of uncertainty and dislike fluctuations in expected consumption growth rates. With transitory shocks and $\gamma>\frac{1}{\psi}$, this second risk factor acts as a hedge for shocks to realized consumption growth and therefore reduces the price of risk. This raises the possibility that if agents like fluctuations in expected consumption growth rates, that is when $\gamma<\frac{1}{\psi}$, consumption smoothing increases the price of risk when technology shocks are transitory. The question is whether this channel can give rise to long-run risks that help in explaining asset prices with a low elasticity of intertemporal substitution. The short answer is yes. However, a low EIS unfortunately gives rise to a risk-free rate puzzle (Weil, 1989). A detailed analysis of this case is given in the appendix.

\section{Empirical Tests: Expected Consumption Growth and the Cross-Section of Stock Returns}

We test key predictions of the model for the time series of technology (total factor productivity) and consumption growth, as well as for the cross-section of stock returns. In particular, we test whether proxies for expected consumption growth suggested by our model actually forecast long-horizon consumption growth or not, whether shocks to expected consumption growth are a priced risk factor or not, and whether the price of risk is positive or negative.

In a recent paper, Bansal, Kiku, and Yaron (2006) test the exchange economy version of the model in this paper and show that consumption growth is indeed predictable using forecasting variables such as lagged consumption growth, the default spread, and the market price-dividend ratio. Furthermore, they show, using the cross-section of stock returns, that shocks to expected consumption growth are indeed a positively priced risk factor. We therefore confine our empirical analysis to test restrictions that are particular to the production

\footnotetext{
${ }^{19}$ Kaltenbrunner (2006) incorporates a search and matching model into standard production economy models with habit preferences in order to jointly explain macroeconomic time series, including labor market series, and asset prices.
} 
economy. We consider an instrument Bansal, Kiku, and Yaron do not use and which is related to the level of technology - the driving process of the production economy model.

The consumption data and data on Total Factor Productivity (TFP; the equivalent to "technology" in our model) are obtained from the Bureau of Economic Analysis and the Bureau of Labor Statistics, respectively. The return data are from Kenneth French's homepage.

\subsection{Expected Consumption Growth}

As highlighted by Harvey and Shepard (1990), Bansal and Yaron (2004) and Hansen, Heaton and $\mathrm{Li}$ (2005), amongst others, it is difficult to estimate long-run consumption growth dynamics from the relatively short samples of data we have available. In our model, slow-moving expected consumption growth dynamics arise due to endogenous consumption smoothing, and the production economy model therefore identifies observable proxies for the otherwise unobservable expected consumption growth rate. In particular, the ratio of the level of technology to the level of consumption forecasts future consumption growth with a positive sign when technology shocks are permanent. This intuition is confirmed in Figure 2, which shows the impulse-response of consumption to a one standard deviation permanent shock to technology (total factor productivity) for high and low levels of the EIS. Investors respond to a technology shock by increasing investment in order to build up higher levels of capital. Thus, while technology immediately adjusts to its new permanent level, consumption only slowly grows to a permanently higher level as capital needs to be built up to support the new steady state consumption level.

In particular, define:

$$
z c_{t} \equiv \ln \left(\frac{Z_{t}}{C_{t}}\right)
$$

If $z c_{t}$ is high, consumption is more likely to increase towards a new steady-state level. Our model thus implies that $z c_{t}$ is a good instrument for the expected consumption growth rate. Our model predicts that $z c_{t}$ is stationary even though both $Z_{t}$ and $C_{t}$ are non-stationary $(I(1))$, because $C_{t}$ evolves around the stochastic trend $Z_{t}$ : If the production technology is specified as:

$$
Y_{t}=Z_{t}^{1-\alpha} K_{t}^{\alpha} N_{t}^{1-\alpha}
$$

as is the case in our model, all endogenous variables in the economy evolve around the stochastic trend $Z_{t}$ (see Appendix 9.5). We get data on $Z_{t}$ (TFP) from the Bureau of Labor Statistics (BLS). The BLS computes TFP as follows. First it collects data on $Y_{t}$ (output), 


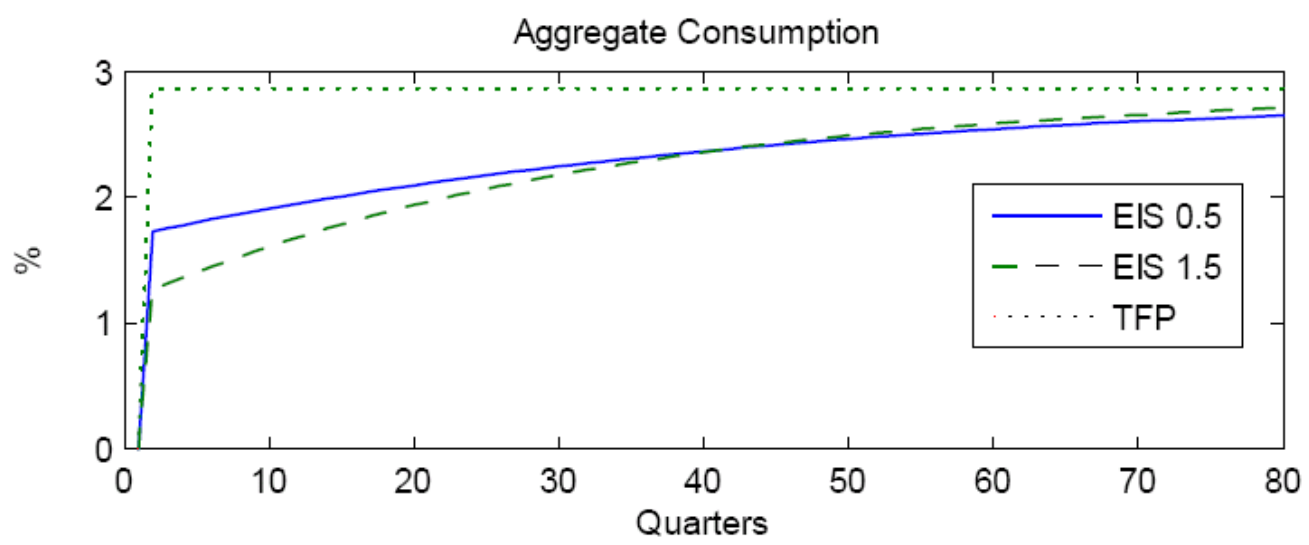

Figure 2: Impulse-Response of Consumption Impulse responses of consumption to a one standard deviation positive and permanent shock to technology for different levels of the EIS. The impulse-responses are for Model $5(\mathrm{EIS}=0.5)$ and Model $6(\mathrm{EIS}=1.5)$, respectively.

on $K_{t}$ (capital input), and on $N_{t}$ (labor input). Then the BLS estimates a value for the parameter $\alpha$ and computes TFP as the Solow residual:

$$
\ln \widetilde{Z}_{t}=\ln Y_{t}-\alpha \ln K_{t}-(1-\alpha) \ln N_{t}
$$

Note that the BLS specifies the following production technology:

$$
Y_{t}=\widetilde{Z}_{t} K_{t}^{\alpha} N_{t}^{1-\alpha}
$$

It follows that we need to normalize:

$$
Z_{t}=\widetilde{Z}_{t}^{1 /(1-\alpha)}
$$

We take as the value for $\alpha$ the value we use in our model $(\alpha=0.34)$. We check our results for robustness by assuming different values for $\alpha \in[0.30,0.40]$, and find that our results are robust with respect to the choice of $\alpha$.

The Baseline Model, which has permanent technology shocks, suggests the following forecasting relationship:

$$
\Delta c_{t, t+j}=\alpha+\beta z c_{t}+\varepsilon_{t, t+j},
$$

where $\beta>0$. In the model, the relation is not exactly linear, but when simulating data from 
our model (Baseline Model) we find that $z c_{t}$ accounts for more than $99 \%$ of the variation in expected consumption growth in a linear regression. We test this forecasting relationship both on data from 1948 to 2005 and on data generated by our model (Baseline Model). In particular, in Table 6 we report results from forecasting regressions of annual log nondurableand services consumption growth on the lagged log TFP to consumption ratio, our measure of expected consumption growth.

Panel A shows that consumption growth is forecastable by the $z c$-ratio using simulated data from our model. The regression coefficient is increasing with the horizon up to 7 years. The forecasting regression coefficients are found by simulating 10,000 samples of length 58 years, running the regression on each sample, and computing the average regression coefficient. The sample errors are the sample standard deviation of each $\beta$-estimate. Interestingly, the regression coefficient is not significant in any of the regressions using data simulated from the model. The variation in expected consumption growth is too slow-moving for the regressions to on average uncover the forecasting relationship over the relatively short sample period.

Panel B shows the results from the forecasting regressions using real data. Here both the regression coefficients and the $R^{2}$ 's are increasing with the forecasting horizon. The coefficients are significant at the $10 \%$ level for all regressions using Hodrick (1992) standard errors, which have relatively good small sample properties for overlapping regressions. The coefficients are overall lower than those estimated using simulated data. This could be because there is less variation in expected consumption growth in the data or because the empirical $z c-$ ratio is measured with noise. ${ }^{20}$

We conclude that the log TFP to consumption ratio, a measure of expected consumption growth implied by our theoretical model, forecasts future consumption growth and that the level of measured variation in expected consumption growth is similar in magnitude to that implied by our model with $\gamma=5$ and $\psi=1.5$.

\subsection{The Cross-Section of Stock Returns}

The model in this paper implies that the shock to expected consumption growth is a priced risk factor as long as $\gamma \neq \frac{1}{\psi}$, i.e. as long as agents care about the temporal resolution of risk.

\footnotetext{
${ }^{20}$ The $R^{2}$ 's are higher for the long-horizon regressions than predicted by the model, although Valkanov (2003) cautions that $R^{2}$ 's are badly behaved in small samples where the fraction of overlapping observations relative to the total sample length is large. Thus, the sample $R^{2}$ 's are likely to overstate somewhat the true $R^{2}$ s.
} 


\section{Table 6}

\section{Estimating Expected Consumption Growth}

Table 6: This table reports forecasting regressions of annual log nondurable- and services consumption growth on a lagged measure of expected consumption growth, the log TFP to Consumption ratio. The consumption and TFP data are from the Bureau of Economic Analysis and the Bureau of Labor Statistics respectively. We use annual data from 1948 to 2005, resulting in 58 - $j$ observations for a regression with a $j$ year forecasting horizon: Multi-year forecasting regressions are overlapping at an annual frequency. The standard error estimates (in parenthesis) are corrected for heteroskedasticity and overlapping observations using Hodrick (1992) standard errors. Results for the model are based on 10,000 replications of sample size $58 \times 4$ each. Numbers in bold indicate significance at the $5 \%$ level or more in a two-tailed t-test, while an asterisk indicates significance at the $10 \%$ level.

Regression: $\Delta c_{t, t+j}=\alpha+\beta z c_{t}+\varepsilon_{t, t+j}$

\begin{tabular}{cccccccr}
\hline \multicolumn{7}{c}{ Panel A: Model implied $(j$ denotes forecasting horizon in years) } \\
$j$ & 1 & 2 & 3 & 4 & 5 & 7 & \multicolumn{1}{c}{10} \\
\hline \multirow{8}{*}{$\beta$} & 0.077 & 0.135 & 0.178 & 0.208 & 0.226 & 0.233 & 0.192 \\
& $(0.051)$ & $(0.101)$ & $(0.151)$ & $(0.201)$ & $(0.251)$ & $(0.345)$ & $(0.468)$ \\
& & & & & & & \\
$R_{\text {adj }}^{2}$ & $9.2 \%$ & $10.2 \%$ & $10.9 \%$ & $10.8 \%$ & $10.3 \%$ & $9.3 \%$ & $8.3 \%$ \\
& $(0.092)$ & $(0.118)$ & $(0.128)$ & $(0.131)$ & $(0.131)$ & $(0.128)$ & $(0.124)$ \\
& & & & & & & \\
\hline
\end{tabular}

Panel B: Historical estimates ( $j$ denotes forecasting horizon in years)

\begin{tabular}{lccccccc}
$j$ & 1 & 2 & 3 & 4 & 5 & 7 & 10 \\
\hline$\beta$ & $0.021^{*}$ & $0.041^{*}$ & $0.060^{*}$ & $0.084^{*}$ & $0.107^{*}$ & $0.147^{*}$ & $0.233^{*}$ \\
& $(0.012)$ & $(0.024)$ & $(0.036)$ & $(0.048)$ & $(0.060)$ & $(0.085)$ & $(0.127)$ \\
$R_{a d j}^{2}$ & $3.3 \%$ & $5.5 \%$ & $7.6 \%$ & $11.1 \%$ & $13.8 \%$ & $17.6 \%$ & $30.0 \%$ \\
\hline
\end{tabular}


The cross-section of stock returns can tell us both whether shocks to expected consumption growth are a priced risk factor and whether the price of risk on this factor is positive or negative, which in turn depends on whether the relative risk aversion of the representative agent is smaller or larger then the reciprocal of the elasticity of substitution and on the persistence of the technology shocks. To relate the consumption dynamics directly to the stochastic discount factor, we assume that the dynamic behavior of consumption growth generated by the model follows:

$$
\begin{aligned}
\Delta c_{t+1} & =\mu+x_{t}+\eta_{t+1}, \\
x_{t+1} & =\rho x_{t}+e_{t+1}, \\
\sigma_{\eta, e} & =\operatorname{corr}\left(e_{t+1}, \eta_{t+1}\right) .
\end{aligned}
$$

We verify in the appendix that this parsimonious specification captures the true behavior of consumption growth from our model well. Given the consumption dynamics in (19) and log-linearizing the return on the wealth portfolio around the steady state ratio of wealth to aggregate consumption, the stochastic discount factor can be written:

$$
m_{t+1} \approx a-b_{1} \Delta c_{t+1}-b_{2} e_{t+1}-b_{3} x_{t}
$$

where $\Delta c_{t+1}$ denotes realized consumption growth, $x_{t}$ is the current level of expected consumption growth, $e_{t+1}$ is the shock to expected consumption growth, and $b_{1}=\gamma, b_{2}=$ $(1-\theta) A_{1} \kappa_{1}, b_{3}=(\theta-1) A_{1}\left(1-\kappa_{1} \rho\right)$ (see the appendix for a detailed derivation and definitions of the constants $A_{1}, \kappa_{1}>0$. If $\gamma>\frac{1}{\psi}$, the coefficients $b_{1}, b_{2}>0$ and $b_{3}<0$. We will test these restrictions using the cross-section of stock returns.

We use the log ratio of TFP to consumption, $z c_{t}$, to obtain measures of $x_{t}$ and $e_{t+1}$ from the following regressions:

$$
\begin{aligned}
\Delta c_{t+1} & =\hat{k}_{0}+\hat{k}_{1} z c_{t}+\hat{\eta}_{t+1}, \\
\widehat{x}_{t} & =\hat{k}_{1}\left(z c_{t}-E_{T}\left[z c_{t}\right]\right) \\
z c_{t+1} & =\hat{k}_{3}+\hat{k}_{4} z c_{t}+\hat{\nu}_{t+1} \\
\widehat{e}_{t+1} & =\hat{k}_{1}\left[z c_{t+1}-\hat{k}_{3}-\hat{k}_{4} z c_{t}\right]
\end{aligned}
$$

where $E_{T}[\cdot]$ denotes the sample mean and $\hat{k}_{i}$ is an OLS regression coefficient. The permanent shock model predicts that shocks to realized $(\hat{\eta})$ and expected $(\hat{e})$ consumption are positively 
correlated, which we confirm is the case in our sample.

By applying a standard log-linear approximation of the stochastic discount factor (see appendix), we arrive at the linear factor model:

$$
\begin{aligned}
E\left[R_{i, t+1}-R_{0, t+1}\right]= & b_{1} \operatorname{Cov}\left(\Delta c_{t+1}, R_{i, t+1}-R_{0, t+1}\right)+b_{2} \operatorname{Cov}\left(e_{t+1}, R_{i, t+1}-R_{0, t+1}\right) \\
& +b_{3} \operatorname{Cov}\left(x_{t}, R_{i, t+1}-R_{0, t+1}\right) .
\end{aligned}
$$

The standard consumption-based asset pricing model with power utility implies that $b_{1}=$ $\gamma=\frac{1}{\psi}$, while $b_{2}=b_{3}=0$. As noted above, if $\gamma>\frac{1}{\psi}$, however, $b_{2}>0$ and $b_{3}<0$.

Because TFP data are only available on an annual basis from the Bureau of Economic Analysis, we use annual returns on the 25 Fama-French portfolios as test assets along with the risk-free rate (U.S. t-Bill). The sample consists of 57 observations from 1948 to 2005. Table 7 displays results for the benchmark Consumption CAPM $\left(b_{2}=b_{3}=0\right)$ and the three-factor model of this paper.

Table 7 displays the sign of the estimated quantities with p-values in parentheses. The factor loading on realized consumption growth risk is insignificant for the standard Consumption CAPM model and the adjusted cross-sectional $R^{2}$ is $17.4 \%$. The three-factor model including measures of the level and the shock to expected consumption growth increases the adjusted $R^{2}$ to $46.6 \%$. The factor loading on the shock to expected consumption growth carries a positive sign and is significant at the $10 \%$ level. The sign on the coefficient on the measure of expected consumption growth $\left(b_{3}\right)$ is negative as predicted, but not quite significant. The power utility benchmark implies that $b_{2}=b_{3}=0$. A test of this joint hypothesis yields a p-value of 0.06 . Thus, the statistical evidence is not very strong, but significant at the $10 \%$ level. On the other hand, we are relying on a noisy proxy and the sample is fairly small.

We conclude that the linear three-factor model derived from our theoretical model outperforms the benchmark Consumption CAPM. We reject the null hypothesis that long-run risk is not important relative to the standard Consumption CAPM for the cross-section of stock returns. The signs on factor loadings $b_{2}$ and $b_{3}$ are consistent with a model where agents prefer early resolution of uncertainty $\left(\gamma>\frac{1}{\psi}\right)$. 


\section{The Price of Long-Run Risk from Cross-Sectional Regressions}

Table 7: This table reports the estimated loadings on the factors of the Consumption CAPM and the long-run risk production-based model developed in this paper (Prod.CAPM). Test assets are the 25 Fama-French portfolios sorted by size and book-to-market equity ratios. All variables are annual. There are 57 observations from 1949 - 2005. Estimation is by two-pass regression, where the standard errors are corrected for generated regressors (Shanken, 1992). P-values are reported for each variable, where the null hypothesis is that the estimate is zero. Numbers in bold indicate significance at the $10 \%$ level or more in a two-tailed t-test.

\begin{tabular}{|c|c|c|}
\hline Tests of Factor Significance: & \multicolumn{2}{|c|}{$m_{t+1}=a-b_{1} \Delta c_{t+1}-b_{2} e_{t+1}-b_{3} x_{t}$} \\
\hline Factor loading $b$ & Cons.CAPM & Prod.CAPM \\
\hline $\begin{array}{l}\text { Realized Cons. Growth }\left(b_{1}\right) \\
\text { (p-value) }\end{array}$ & $\begin{array}{l}>0 \\
(0.24)\end{array}$ & $\begin{array}{c}<0 \\
(0.82)\end{array}$ \\
\hline $\begin{array}{l}\text { Shock to Exp. Cons. Growth }\left(b_{2}\right) \\
\text { (p-value) }\end{array}$ & & $\begin{array}{c}>0 \\
(0.09)\end{array}$ \\
\hline $\begin{array}{l}\text { Expected Cons. Growth }\left(b_{3}\right) \\
\text { (p-value) }\end{array}$ & & $\begin{array}{l}<0 \\
(0.11)\end{array}$ \\
\hline $\begin{array}{l}\text { Joint test: } b_{2}=b_{3}=0 \\
\text { (p-value) }\end{array}$ & & $\begin{array}{l}\text { reject } \\
(\mathbf{0 . 0 6})\end{array}$ \\
\hline$R_{a d j}^{2}$ & $17.4 \%$ & $46.7 \%$ \\
\hline
\end{tabular}




\section{Conclusion}

We analyze a standard stochastic growth model where agents have Epstein-Zin preferences. We show that long-run risk arises endogenously as a consequence of consumption smoothing, even though log technology follows a random walk. When the coefficient of relative risk aversion is greater than the reciprocal of the elasticity of intertemporal substitution, agents dislike negative shocks to future economic growth prospects and shocks to expected consumption growth appear as a risk factor. The presence of long-run risk in this case decreases the market price of risk if technology shocks are transitory, while it increases the market price of risk if technology shocks are permanent. The model therefore provides a theoretical justification for a long-run risk component in aggregate consumption growth. This result is of particular interest since it is very difficult to empirically distinguish a small predictable component of consumption growth from i.i.d. consumption growth given the short sample of data we have available.

We calibrate the model to key aggregate macroeconomic moments and show that we can match the level and volatility of the risk-free rate and the unconditional equity Sharpe ratio. The model achieves this with a low level of relative risk aversion, unlike habit formation models where typical implementations also generate too much volatility in the risk-free rate. The elasticity of intertemporal substitution, which strongly affects the dynamics of the macroeconomic variables, also strongly affects the price of risk and the Sharpe ratio of equity in the model. Thus, there is a tight link between quantity dynamics and asset prices in our implementation of the standard stochastic growth model.

The production economy model identifies the ratio of technology to consumption as a proxy for the otherwise hard to estimate expected consumption growth. We test this link in the time-series of consumption growth and in the cross-section of stock returns. We find support for both tests. In particular, the production-based CAPM outperforms the standard CCAPM in a cross-sectional test. The parameter estimates obtained from the cross-sectional analysis are consistent with a model where technology shocks are permanent and agents have a preference for early resolution of uncertainty.

\section{References}

Abel, Andrew B. "Asset Prices under Habit Formation and Catching Up with the Joneses." American Economic Review, May 1990, 80(2), pp. 38-42. 
Backus, David K. and Zin, Stanley E. "Reverse Engineering the Yield Curve." NBER Working Paper No. 4676, 1994.

Bansal, Ravi; Kiku D. and Yaron, Amir. "Risks for the Long Run: Estimation and Inference." Working paper, Duke University, 2006.

Bansal, Ravi and Yaron, Amir. "Risks for the Long Run: A Potential Resolution of Asset Pricing Puzzles." Journal of Finance, August 2004, 59(4), pp. 1481-1509.

Bansal, Ravi; Dittmar, Robert F. and Lundblad, Christian T. "Consumption, Dividends, and the Cross-Section of Equity Returns." Journal of Finance, 2004, 60, pp. 1639-1672.

Barsky, Robert and DeLong, Bradford J. "Why Does the Stock Market Fluctuate?" Quarterly Journal of Economics, May 1993, 108(2), pp. 291-312.

Boldrin, Michele; Christiano, Lawrence J. and Fisher, Jones D.M. "Habit Persistence, Asset Returns, and the Business Cycle." American Economic Review, March 2001, 91(1), pp. 149-166.

Boldrin, Michele; Christiano, Lawrence J. and Fisher, Jones D.M. "Habit Persistence, Asset Returns, and the Business Cycle." Working Paper, 1999.

Campbell, John Y. "Asset Prices, Consumption, and the Business Cycle." Handbook of Macroeconomics, 1999, Volume 1, Chapter 19, pp. 1231-1303.

Campbell, John Y. "Inspecting the Mechanism. An Analytical Approach to the Stochastic Growth Model." Journal of Monetary Economics, 1994, 33, pp. 463-506.

Cochrane, John. "Financial Markets and the Real Economy." Foundations and Trends in Finance, 2005, 1(1), pp. 1-101.

Cochrane, John. "Asset Pricing." Princeton University Press, 2001.

Cochrane, John and Hansen, Lars. "Asset Pricing Explorations for Macroeconomics" In: Olivier Blanchard and Stanley Fisher (Eds.), NBER Macroeconomics Annual, 1992, pp. 115-165.

Cooley, Thomas F. and Prescott, Edward C. "Economic Growth and Business Cycles." In: Thomas Cooley F. (Ed.), Frontiers of Business Cycle Research. Princeton University Press, Princeton, NJ, 1995, pp. 1-37.

Den Haan, Wouter J. "The Term Structure of Interest Rates in Real and Monetary Economics." Journal of Economic Dynamics and Control, 1995, 19(5/6), pp. 910-940.

Den Haan, Wouter J. and Kaltenbrunner, Georg. "Anticipated Growth and Business Cycles in Matching Models." Working Paper, 2006.

Den Haan, Wouter J.; Ramey, Garey and Watson, Joel. "Job Destruction and 
Propagation of Shocks." American Economic Review, June 2000, 90(3), pp. 482-498.

Duffie, Darrell and Epstein, Larry G. "Stochastic Differential Utility." Econometrica, 1992, 60, pp. 353-394.

Epstein, Larry G. and Zin, Stanley E. "Substitution, Risk Aversion, and the Temporal Behavior of Consumption and Asset Returns: An Empirical Analysis." Journal of Political Economy, 1991, 99(2), pp. 263-286.

Epstein, Larry G. and Zin, Stanley E. "Substitution, Risk Aversion, and the Temporal Behavior of Consumption and Asset Returns: A Theoretical Framework." Econometrica, 1989, 57(4), pp. 937-969.

Friedman, Milton. "A Theory of the Consumption Function." NBER, Princeton, 1957.

Gomes, Francisco and Michaelides, Alex. "Asset Pricing with Limited Risk Sharing and Heterogeneous Agents." Working Paper, London Business School, 2006.

Hall, Robert E. "Stochastic Implications of the Life Cycle-Permanent Income Hypothesis: Theory and Evidence." Journal of Political Economy, December 1978, 86(6), pp. 971-987.

Hall, Robert E. "Employment Fluctuations with Equilibrium Wage Stickiness." American Economic Review, March 2005, 95(1), pp. 50-65.

Hamilton, James D. "Time Series Analysis." Princeton University Press, 1994.

Hansen, Lars Peter; Heaton, John C. and Li, Nan. "Consumption Strikes Back?: Measuring Long Run Risk." Working Paper, 2005.

Harvey, Andrew C. and Shepard, Neil G. "On the Probability of Estimating a Deterministic Component in the Local Level Model." Journal of Time Series Analysis, 1990, 11, pp. 339-347.

Hodrick, Robert J. "Dividend Yields and Expected Stock Returns: Alternative Procedures for Inference and Measurement." Review of Financial Studies, 1992, 5(3), pp. 357-386. Hornstein, Andreas; Krusell, Per and Violante, Giovanni L. "Unemployment and Vacancy Fluctuations in the Matching Model: Inspecting the Mechanism." Economic Quarterly (Federal Reserve Bank of Richmond), Summer 2005, 91(3), pp. 19-51.

Jermann, Urban J. "Asset Pricing in Production Economies." Journal of Monetary Economics, April 1998, 41(2), pp. 257-275.

Kaltenbrunner, Georg. "Asset Pricing in Production Economies - A Matching Model." Working Paper, London Business School, 2006.

Kydland, Finn E. and Prescott, Edward C. "Time to Build and Aggregate Fluctuations." Econometrica, November 1982, 50(6), pp. 1345-1370.

Lettau, Martin and Uhlig, Harald. "Can Habit Formation be Reconciled with Business 
Cycle Facts?" Review of Economic Dynamics, January 2000, 3(1), pp. 79-99.

Long, John B. and Plosser, Charles I. "Real Business Cycles." Journal of Political Economy, February 1983, 91, pp. 39-69.

Lucas, Robert E. "Asset Prices in an Exchange Economy." Econometrica, November 1978, 46(6), pp. 1429-1445.

Malloy, Christopher; Moskowitz, Tobias J. and Vissing-Jorgensen, Annette. "Long-Run Stockholder Consumption Risk and Asset Returns." Working Paper, 2005.

Mehra, Rajnish and Prescott, Edward C. "The Equity Premium: A Puzzle." Journal of Monetary Economics, March 1985, 15, pp. 145-161.

Mortensen, Dale T. and Pissarides, Christopher A. "Job Creation and Job Destruction in the Theory of Unemployment." Review of Economic Studies, July 1994, 61(3), pp. 269-300.

Panageas, Stavros and Yu, Jianfeng. "Technological Growth, Asset Pricing, and Consumption Risk over Long Horizons." Wharton Working Paper, 2005.

Parker, Jonathan A. and Julliard, Christian. "Consumption Risk and the Cross Section of Expected Returns." Journal of Political Economy, 2005, 115(1), pp. 185-222.

Prescott, Edward C. "Theory Ahead of Business Cycle Measurement." Carnegie-Rochester Conference Series on Public Policy, 1986, 25, pp. 11-66.

Restoy, Fernando and Rockinger, Michael. "On Stock Market Returns and Returns on Investment." Journal of Finance, June 1994, 49(2), pp. 543-556.

Rouwenhorst, Geert K. "Asset Pricing Implications of Equilibrium Business Cycle Models." In: Thomas Cooley F. (Ed.), Frontiers of Business Cycle Research. Princeton University Press, Princeton, NJ, 1995, pp. 294-329.

Rubinstein, Mark. "The Valuation of Uncertain Income Streams and the Pricing of Options." Bell Journal of Economics and Management Science, 1976, 7(2), pp. 407-425.

Shanken, Jay. "On the Estimation of Beta-Pricing Models." Review of Financial Studies, 1992, 5(1), pp. 1-33.

Shimer, Robert. "The Cyclical Behavior of Equilibrium Unemployment and Vacancies." American Economic Review, March 2005, 95(1), pp. 25-49.

Storesletten, Kjetil; Telmer, Chris and Yaron, Amir. "Asset Pricing with Idiosyncratic Risk and Overlapping Generations." Working Paper, Carnegie Mellon University, 2001.

Tallarini, Thomas D. Jr. "Risk-Sensitive Real Business Cycles." Journal of Monetary Economics, June 2000, 45(3), pp. 507-532. 
Uhlig, Harald. "Macroeconomics and Asset Markets: Some Mutual Implications." Working Paper, 2004.

Valkanov, R. "Long Horizon Regressions: Theoretical Results and Applications", Journal of Financial Economics, 68, 2003, 201-232

Weil, Philippe. "The Equity Premium Puzzle and the Risk-free Rate Puzzle." Journal of Monetary Economics, November 1989, 24, pp. 401-421.

Yogo, Motohiro. "A Consumption-Based Explanation of Expected Stock Returns." Journal of Finance, April 2006, 61(2), forthcoming.

Zhang, Lu. "The Value Premium." Journal of Finance, February 2005a, 60(1), pp. 67-103.

Zhang, Lu. "Anomalies." Working Paper, 2005b.

\section{Appendix}

\subsection{Model Solution}

The Return to Investment and the Firm's Problem The firm maximizes firm value. Let $M_{t, t+1}$ denote the stochastic discount factor. The firm's problem is then:

$$
\max _{\left\{I_{t}, K_{t+1}, H_{t}\right\}_{t=0}^{T}} E_{0}\left[\sum_{t=0}^{T} M_{0, t}\left\{\begin{array}{c}
\left(Y_{t}-W_{t} H_{t}-I_{t}\right)- \\
q_{t}\left(K_{t+1}-(1-\delta) K_{t}-\phi\left(\frac{I_{t}}{K_{t}}\right) K_{t}\right)
\end{array}\right\}\right],
$$

where $q_{t}$ denotes the shadow price of the capital accumulation constraint, equivalent to marginal $q$ : The expected present value of one marginal unit of capital. Maximizing over labor we obtain $(1-\alpha) Z_{t}^{1-\alpha} K_{t}^{\alpha} H_{t}^{-\alpha}=W_{t}$ and $H_{t}=(1-\alpha)^{\frac{1}{\alpha}} Z_{t}^{\frac{1}{\alpha}-1} W_{t}^{-\frac{1}{\alpha}} K_{t}$. In other words, we assume an exogenous wage process such that it is optimal for the firm to always hire at full capacity $\left(H_{t}=1\right)$, which is the same amount of labor as the representative agent is assumed to supply. In this case, total wages $W_{t} H_{t}=W_{t}=(1-\alpha) Y_{t}$, so wages are pro-cyclical and have the same growth rate volatility as total output. The operating profit function of the 
firm follows as:

$$
\begin{aligned}
\Pi\left(K_{t}, Z_{t} ; W_{t}\right) & =Z_{t}^{1-\alpha}\left[(1-\alpha)^{\frac{1}{\alpha}} Z_{t}^{\frac{1}{\alpha}-1} W_{t}^{-\frac{1}{\alpha}} K_{t}\right]^{1-\alpha} K_{t}^{\alpha}-W_{t}(1-\alpha)^{\frac{1}{\alpha}} Z_{t}^{\frac{1}{\alpha}-1} W_{t}^{-\frac{1}{\alpha}} K_{t} \\
& =Z_{t}^{1-\alpha}\left[(1-\alpha)^{\frac{1}{\alpha}} Z_{t}^{\frac{1}{\alpha}-1} W_{t}^{-\frac{1}{\alpha}}\right]^{1-\alpha} K_{t}-(1-\alpha)^{\frac{1}{\alpha}} Z_{t}^{\frac{1}{\alpha}-1} W_{t}^{1-\frac{1}{\alpha}} K_{t} \\
& =\left((1-\alpha)^{\frac{1}{\alpha}-1} Z_{t}^{\frac{1}{\alpha}-1} W_{t}^{1-\frac{1}{\alpha}}-(1-\alpha)^{\frac{1}{\alpha}} Z_{t}^{\frac{1}{\alpha}-1} W_{t}^{1-\frac{1}{\alpha}}\right) K_{t} \\
& =\left(\alpha(1-\alpha)^{\frac{1}{\alpha}-1} Z_{t}^{\frac{1}{\alpha}-1} W_{t}^{1-\frac{1}{\alpha}}\right) K_{t}
\end{aligned}
$$

The operating profit function of the firm is thus linearly homogenous in capital. Substituting out equilibrium wages we obtain $\Pi\left(K_{t}, Z_{t} ; W_{t}\right)=\alpha Y_{t}$. We re-state the firm's problem:

$$
\max _{\left\{I_{t}, K_{t+1}\right\}_{t=0}^{\infty}} E_{0}\left[\sum_{t=0}^{\infty} M_{0, t}\left\{\Pi(\cdot)-I_{t}-q_{t}\left(K_{t+1}-(1-\delta) K_{t}-\phi\left(\frac{I_{t}}{K_{t}}\right) K_{t}\right)\right\}\right] .
$$

Each period in time the firm decides how much to invest, taking marginal $q$ as given. The first order conditions with respect to $I_{t}$ and $K_{t+1}$ are immediate:

$$
\begin{aligned}
0= & -1+q_{t} \phi^{\prime}\left(\frac{I_{t}}{K_{t}}\right), \\
& \text { and } \\
0= & -q_{t}+E_{t}\left[M _ { t + 1 } \left\{\begin{array}{c}
\Pi_{K}(\cdot) \\
\left.\left.+q_{t+1}\left((1-\delta)-\phi^{\prime}\left(\frac{I_{t+1}}{K_{t+1}}\right) \frac{I_{t+1}}{K_{t+1}}+\phi\left(\frac{I_{t+1}}{K_{t+1}}\right)\right)\right\}\right] .
\end{array}\right.\right.
\end{aligned}
$$

Substituting out $q_{t}$ and $q_{t+1}$ in (34) yields:

$$
\begin{aligned}
\frac{1}{\phi^{\prime}\left(\frac{I_{t}}{K_{t}}\right)} & =E_{t}\left[M_{t+1}\left\{\Pi_{K}(\cdot)+\frac{(1-\delta)-\phi^{\prime}\left(\frac{I_{t+1}}{K_{t+1}}\right) \frac{I_{t+1}}{K_{t+1}}+\phi\left(\frac{I_{t+1}}{K_{t+1}}\right)}{\phi^{\prime}\left(\frac{I_{t+1}}{K_{t+1}}\right)}\right\}\right], \\
1 & =E_{t}\left[M_{t+1}\left\{\phi^{\prime}\left(\frac{I_{t}}{K_{t}}\right)\left(\Pi_{K}(\cdot)+\frac{1-\delta+\phi\left(\frac{I_{t+1}}{K_{t+1}}\right)}{\phi^{\prime}\left(\frac{I_{t+1}}{K_{t+1}}\right)}-\frac{I_{t+1}}{K_{t+1}}\right)\right\}\right], \\
1 & =E_{t}\left[M_{t+1} R_{t+1}^{I}\right] .
\end{aligned}
$$


Equation (37) is the familiar law of one price, with the firm's return to investment:

$$
R_{t+1}^{I}=\phi^{\prime}\left(\frac{I_{t}}{K_{t}}\right)\left(\Pi_{K}\left(K_{t+1}, Z_{t+1} ; W_{t+1}\right)+\frac{1-\delta+\phi\left(\frac{I_{t+1}}{K_{t+1}}\right)}{\phi^{\prime}\left(\frac{I_{t+1}}{K_{t+1}}\right)}-\frac{I_{t+1}}{K_{t+1}}\right) .
$$

\subsection{Risk and the Dynamic Behavior of Consumption}

Epstein-Zin preferences have been used with increasing success in the asset pricing literature over the last years (e.g., Bansal and Yaron, 2004, Hansen, Heaton and Li, 2005, Malloy, Moskowitz and Vissing-Jorgensen, 2005, Yogo, 2006). This is both due to their recursive nature, which allows time-varying growth rates to increase the volatility of the stochastic discount factor through the return on the wealth portfolio, as well as the fact that these preferences allow a convenient separation of the elasticity of intertemporal substitution from the coefficient of relative risk aversion.

Departing from time-separable power utility preferences with $\gamma=\frac{1}{\psi}$ means agents care about the temporal distribution of risk. In particular, Epstein and Zin (1989) show that $\gamma>\frac{1}{\psi}$ implies a preference for early resolution of uncertainty. This is a key assumption of our analysis, because it is precisely this departure from the classic preference structure that renders time-varying expected consumption growth rates induced by optimal consumption smoothing behavior a priced risk factor in the economy.

\subsubsection{Early Resolution of Uncertainty and Aversion to Time-Varying Growth Rates}

To gain some intuition for why a preference for early resolution of uncertainty implies aversion to time-varying growth rates, we revisit an example put forward in Duffie and Epstein (1992). Consider a world where each period of time consumption can be either high or low. Next, the consumer is given a choice between two consumption gambles, $A$ and $B$. Gamble $A$ entails eating $C_{0} \equiv \frac{1}{2} C^{H}+\frac{1}{2} C^{L}$ today, where $C^{H}$ is a high consumption level and $C^{L}$ is a low consumption level. Tomorrow you flip a fair coin. If the coin comes up heads, you will get $C^{H}$ each period forever. If the coin comes up tails, you will get $C^{L}$ each period forever. Gamble $B$ entails eating $C_{0}$ today, and then flip a fair coin each subsequent period $t$. If the coin comes up heads at time $t$, you get $C^{H}$ at time $t$, and if it comes out tails, you get $C^{L}$ at time $t$. Thus, in the first case uncertainty about future consumption is resolved early, while in the second case uncertainty is resolved gradually (late). If $\gamma=\frac{1}{\psi}$ (power utility), 
the consumer is indifferent with respect to the timing of the resolution of uncertainty and thus indifferent between the two gambles. However, an agent who prefers early resolution of uncertainty (i.e., she likes to plan), prefers gamble $A$.

We can now also phrase this discussion in terms of growth rates. From this perspective, gamble $A$ has constant expected consumption growth, while gamble $B$ has a mean-reverting process for expected consumption growth. Thus, a preference for early resolution of uncertainty translates into an aversion of time-varying expected consumption growth.

Another, more mechanical, way to see this is by directly looking at the stochastic discount factor. It is well known, e.g. Rubinstein (1976), that the stochastic discount factor, $M_{t+1}$, is the ratio of the representative agent's marginal utility between today and tomorrow: $M_{t+1}=\frac{U^{\prime}\left(C_{t+1}\right)}{U^{\prime}\left(C_{t}\right)}$. Using a recursive argument, Epstein and Zin (1989) show that:

$$
\ln M_{t+1} \equiv m_{t+1}=\theta \ln \beta-\frac{\theta}{\psi} \Delta c_{t+1}-(1-\theta) r_{a, t+1}
$$

where $\Delta c_{t+1} \equiv \ln \frac{C_{t+1}}{C_{t}}$ and $r_{a, t+1} \equiv \ln \frac{C_{t+1}+A_{t+1}}{A_{t}}$ is the return on the total wealth portfolio with $A_{t}$ denoting total wealth at time $t .{ }^{21}$ If $\gamma=\frac{1}{\psi}, \theta=\frac{1-\gamma}{1-1 / \psi}=1$, and the stochastic discount factor collapses to the familiar power utility case. However, if the agent prefers early resolution of uncertainty, the return on the wealth portfolio appears as a risk factor. More time-variation in expected consumption growth (the expected "dividends" on the total wealth portfolio) induces higher volatility of asset returns, in turn resulting in a more volatile stochastic discount factor and thus a higher price of risk in the economy. ${ }^{22}$

The effect on the equity premium can be understood by considering a log-linear approximation (see Campbell, 1999) of returns and the pricing kernel, yielding the following expressions for the risk-free rate and the equity premium:

$$
\begin{aligned}
r_{f, t+1} & \approx-\log \beta+\frac{1}{\psi} E_{t}\left[\Delta c_{t+1}\right]-\frac{\theta}{2 \psi^{2}} \sigma_{t, c}^{2}+\frac{(\theta-1)}{2} \sigma_{t, r^{A}}^{2}, \\
E_{t}\left[r_{t+1}^{E}\right]-r_{f, t+1} & \approx \frac{\theta}{\psi} \sigma_{t, r^{E} c}+(1-\theta) \sigma_{t, r^{E} r^{A}}-\frac{\sigma_{t, r^{E}}^{2}}{2}
\end{aligned}
$$

where $E_{t}\left[\triangle c_{t+1}\right]$ is expected log consumption growth, $\sigma_{t, c}, \sigma_{t, r^{A}}, \sigma_{t, r^{E}}$, are the conditional standard deviations of log consumption growth, the log return on the total wealth portfolio,

\footnotetext{
${ }^{21}$ Note that our representative household's total wealth portfolio is composed of the present value of future labor income in addition to the value of the firm.

${ }^{22}$ This assumes that the correlation between the return on the wealth portfolio and consumption growth is non-negative, which it is for all parameter values we consider in this paper (and many more).
} 
and the log equity return, and $\sigma_{t, r} E_{c}$ and $\sigma_{t, r}{ }_{r}{ }^{A}$ are the conditional covariances of the $\log$ equity return with log consumption growth and the log return on the total wealth portfolio respectively. We can see how the level of the equity premium depends directly on the covariance of equity returns with returns on the wealth portfolio.

\subsubsection{Technology and Risk Aversion}

Standard production technologies do not allow agents to hedge the technology shock. Agents must in the aggregate hold the claim to the firm's dividends. Therefore, the only action available to agents at time $t$ in terms of hedging the shock at time $t+1$, is to increase savings in order to increase wealth for time $t+1$. The shock will still hit the agents at time $t+1$ though, no matter what. Wealth levels may be higher if a bad realization of the technology shock hits the agents, but wealth is also higher if a good realization of the technology shock occurs. The difference between the agents' utility for a good realization of the technology shock in period $t+1$ relative to their utility for a bad realization of the shock is thus (almost) unaffected. However, it is this utility difference the agents care about in terms of their risk aversion. Now, because the agents' utility function is concave, this is not quite true. A higher wealth level in both states of the world does decrease the difference between utility levels. Agents thus respond by building up what is referred to as "bufferstock-savings". This is, however, a second-order effect. As a result, the dynamic behavior of consumption growth is largely unaffected by changing agents' coefficient of relative risk aversion. The fundamental consumption risk in the economy remains therefore (almost) the same when we increase risk aversion $(\gamma)$ while holding the EIS $(\psi)$ constant. Asset prices, of course, respond as usual to higher levels of risk aversion.

Table 8 confirms this result. We report Model 3 and the Baseline Model from Table 3 with a coefficient of relative risk aversion $(\gamma)$ of 5 , as well as versions of the models with a higher level of risk aversion $(\gamma=25)$.

\subsection{The Case of $\gamma<\frac{1}{\psi}$}

In the previous discussions our focus was on the case of $\gamma>\frac{1}{\psi}$, where agents prefer early resolution of uncertainty and dislike fluctuations in expected consumption growth rates. With transitory shocks and $\gamma>\frac{1}{\psi}$, this second risk factor acts as a hedge for shocks to realized consumption growth and therefore reduces the price of risk. This raises the possibility that if agents like fluctuations in expected consumption growth rates, that is when $\gamma<\frac{1}{\psi}$, 


\section{Table 8}

\section{The Effect of Risk Aversion on Macroeconomic Time Series}

Table 8: This table reports relevant macroeconomic moments and consumption dynamics for models with either transitory $(\varphi=0.90)$ or permanent technology shocks and different levels of the coefficient of relative risk aversion. The elasticity of intertemporal substitution $(\psi)$ is 1.5 across all models. We re-calibrate the discount factor $(\beta)$ for each model so as to jointly match the values for $(\mathrm{C} / \mathrm{Y}),(\mathrm{I} / \mathrm{Y}),(\mathrm{D} / \mathrm{Y})$, with each model. Capital adjustment costs $(\xi)$ are 22 in order to match the relative volatility of consumption to output with the Baseline Model. Model 3 and Model 13 share the same parameter values apart from the coefficient of relative risk aversion $(\gamma)$. The same is true for the Baseline Model and Model 14. We estimate the following process for the consumption dynamics: $\Delta c_{t+1}=\mu+x_{t}+\eta_{t+1}, x_{t+1}=\rho x_{t}+e_{t+1} . \Delta x=\log \left(X_{t}\right)-\log \left(X_{t-1}\right)$, and $\sigma[X]$ denotes the standard deviation of variable $X$. We use annual U.S. data from 1929 to 1998 from the Bureau of Economic Analysis. The sample is the same as in Bansal and Yaron (2004). Under Panel B we report the calibration of the exogenous consumption process Bansal and Yaron use. All values reported in the table are quarterly.

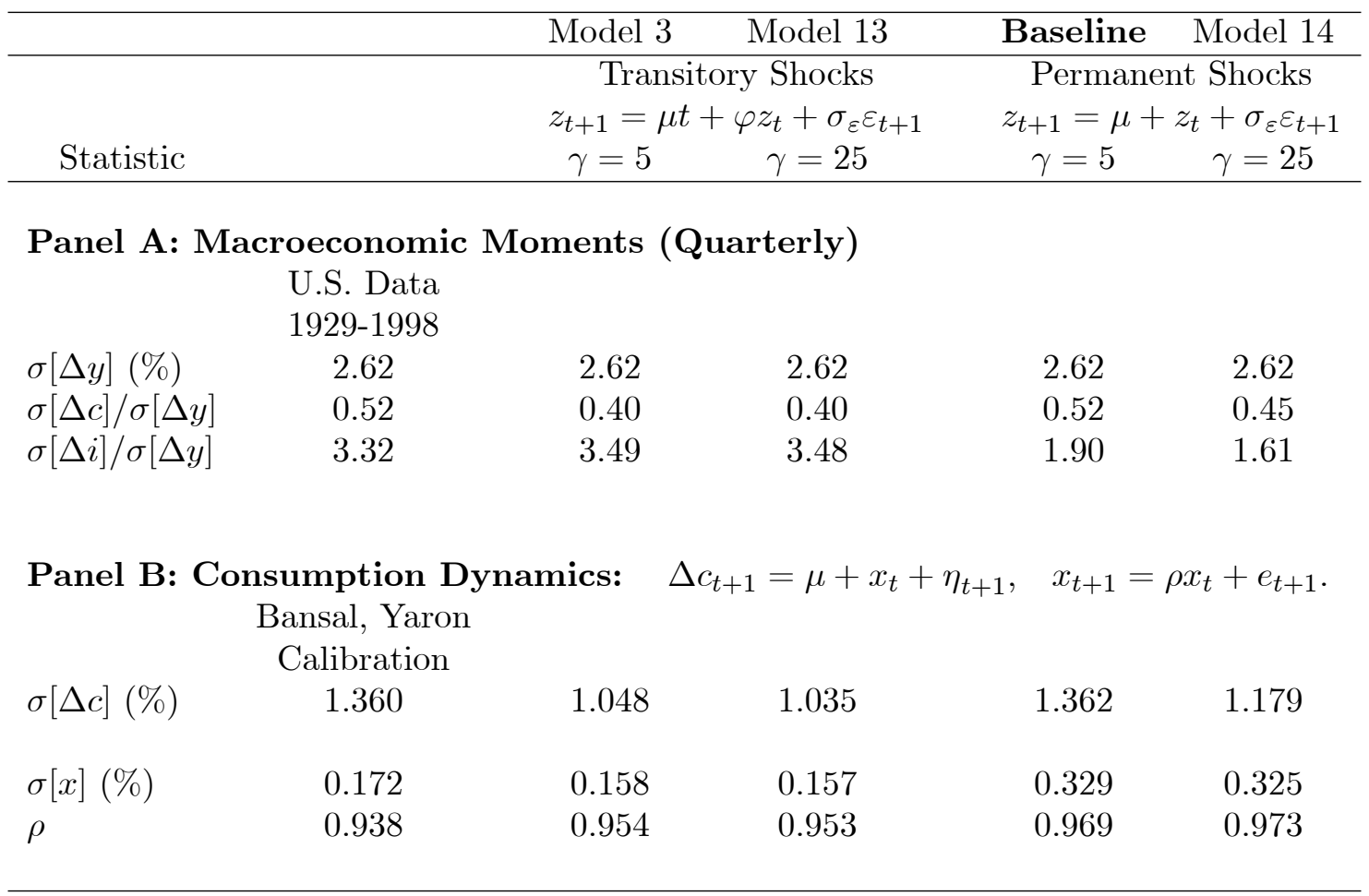


consumption smoothing increases the price of risk when technology shocks are transitory. In this section, we investigate whether this channel can give rise to long-run risks that help in explaining asset prices with a low elasticity of intertemporal substitution. The short answer is yes. However, a low EIS unfortunately gives rise to a risk-free rate puzzle (Weil, 1989).

Table 9 shows calibrated macroeconomic and financial moments from models with $\gamma=5$, and $\psi=\frac{1}{5}$ and $\psi=0.1$. From Model 7 to Model 15 we increase capital adjustment costs in order to fit the relative volatility of consumption to output. Higher capital adjustment costs increase the equity return volatility, as marginal $q$ is now more volatile. From Model 15 to Model 16 we decrease the EIS relative to the benchmark power utility model. A lower EIS induces a higher equity return Sharpe ratio and a higher price of risk due to the preference for time-varying expected consumption growth, which is negatively correlated with shocks to realized consumption growth. In other words, the effect of long-run risk on the price of risk is now decreasing in the EIS, as opposed to the case of permanent technology shocks. Long-run risk with a low EIS is quite different from the intuition in Bansal and Yaron (2004) and may seem surprising given that a low EIS implies that consumers strive to make the consumption path smooth over time and therefore minimize the volatility of expected consumption growth. However, the fact that we are increasing capital adjustment costs to match the macroeconomic moments renders consumption smoothing more costly. Therefore, in equilibrium, a substantial amount of long-run risk remains in the economy even with a low $E I S$. As a result, the price of risk almost doubles relative to the power utility benchmark model. The equity return volatility also increases due to high capital adjustment costs. The net effect is a substantial increase in the equity premium.

Unfortunately, decreasing the elasticity of intertemporal substitution also leads to a riskfree rate puzzle. The average annual risk-free rate is with $7.63 \%$ already much too high in the benchmark power utility model and increases further to $14.92 \%$ as we decrease the EIS. Thus, endogenous long-run risk can substantially improve the asset pricing properties of production economy models even with a very low EIS. However, the risk-free rate is too high given an average annual consumption growth rate of $1.6 \%$ as assumed in this paper. If one is willing to assume that the average real consumption growth rate is close to zero, it would be possible to also fit the average risk-free rate. 


\section{Table 9}

\section{The Case of $\gamma<\frac{1}{\psi}$ : Asset Pricing Implications}

Table 9: This table reports relevant macroeconomic moments, consumption dynamics, and financial moments for models with transitory $(\varphi=0.90)$ technology shocks and different levels of the elasticity of intertemporal substitution. The coefficient of relative risk aversion $(\gamma)$ is 5 and $\beta$ is 0.998 across all models. We re-calibrate $\sigma_{\epsilon}$ in order to match the volatility of consumption growth with each model. We estimate the following process for the consumption dynamics: $\Delta c_{t+1}=\mu+x_{t}+\sigma_{\eta} \eta_{t+1}, x_{t+1}=\rho x_{t}+\sigma_{e} e_{t+1} \cdot \Delta x=\log \left(X_{t}\right)-\log \left(X_{t-1}\right)$, and $\sigma[X]$ denotes the standard deviation of variable $X$. We use annual U.S. data from 1929 to 1998 from the Bureau of Economic Analysis and from Bansal and Yaron (2004). Under Panel B we report the calibration of the exogenous consumption process Bansal and Yaron use.

\begin{tabular}{cccc}
\hline & Model 7 & Model 15 & Model 16 \\
\hline & \multicolumn{3}{c}{ Transitory Shocks } \\
& & $z_{t+1}=\mu t+\varphi z_{t}+\sigma_{\varepsilon} \varepsilon_{t+1}$ \\
\hline Statistic & $\psi=\frac{1}{\gamma}$ & $\psi=\frac{1}{\gamma}$ & $\psi=0.10$ \\
& $\xi=22$ & $\xi=2$ & $\xi=2$ \\
\hline
\end{tabular}

Panel A: Macroeconomic Moments (Quarterly)

$\begin{array}{lcccc} & \text { U.S. Data } & & & \\ & 1929-1998 & & & \\ \sigma[\Delta y](\%) & 2.62 & 4.72 & 2.62 & 2.62 \\ \sigma[\Delta c] / \sigma[\Delta y] & 0.52 & 0.29 & 0.52 & 0.52 \\ \sigma[\Delta i] / \sigma[\Delta y] & 3.32 & 4.83 & 2.88 & 4.03\end{array}$

Panel B: Consumption Dynamics (Quarterly): $\Delta c_{t+1}=\mu+x_{t}+\eta_{t+1}, \quad x_{t+1}=\rho x_{t}+e_{t+1}$.

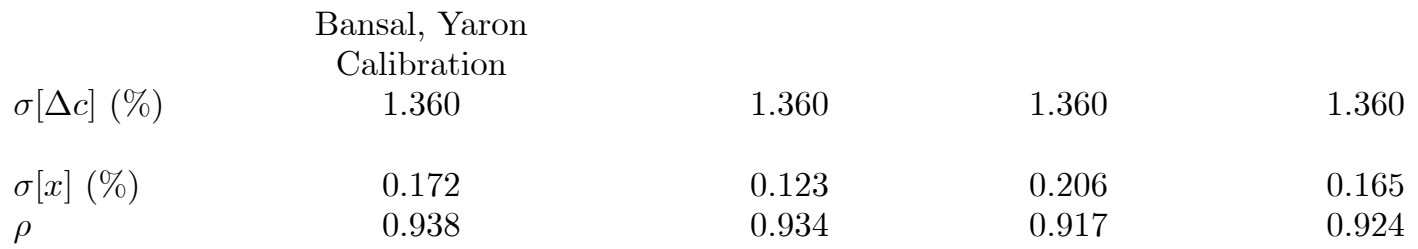

Panel B: Financial Moments (Annual)

$\begin{array}{lcccc}\sigma[M] / E[M] & n / a & 0.13 & 0.13 & 0.19 \\ S R\left[R^{E}\right] & 0.33 & 0.11 & 0.13 & 0.19 \\ E\left[R_{f}\right](\%) & & & & 14.92 \\ \sigma\left[R_{f}\right](\%) & 0.86 & 7.63 & 7.61 & 3.30 \\ & 0.97 & 1.14 & 1.96 & \\ E\left[R^{E}-R_{f}\right](\%) & 6.33 & & & 2.06 \\ \sigma\left[R^{E}-R_{f}\right](\%) & 19.42 & 0.25 & 1.05 & 10.82\end{array}$




\subsection{Accuracy of the Approximation of the Endogenous Consump- tion Process}

In Section 5.1 we propose the following approximation for the dynamics of the endogenous process for consumption:

$$
\begin{aligned}
\Delta c_{t+1} & =\mu+x_{t}+\sigma_{\eta} \eta_{t+1}, \\
x_{t+1} & =\rho x_{t}+\sigma_{e} e_{t+1}, \\
\sigma_{\eta, e} & =\operatorname{corr}\left(\eta_{t+1}, e_{t+1}\right) .
\end{aligned}
$$

Here $\Delta c_{t+1}$ is $\log$ realized consumption growth, $x_{t}$ is the time-varying component of expected consumption growth, and $\eta_{t}, e_{t}$ are zero mean, unit variance, and normally distributed disturbance terms with correlation $\sigma_{\eta, e}$. This functional form for log consumption growth is identical to the one assumed by Bansal and Yaron (2004) as driving process of their exchange economy model. Our results therefore provide a theoretical justification for their particular exogenous consumption growth process assumption. To evaluate whether the above specified process is a good approximation of the true consumption growth dynamics we first estimate the process from simulated data for a whole range of different model calibrations both with random walk- as well as with $\mathrm{AR}(1)$ technology processes. Then we compare the autocorrelation function obtained directly from the simulated data to the one implied by the above specified process which we have imposed on the data.

For the random walk technology the autocorrelation functions are virtually indistinguishable in all cases we have examined. Figure 3 shows this for the Baseline Model. ${ }^{23}$ For the $\mathrm{AR}(1)$ technology the approximation turns out to get worse the lower the persistence of the driving process. Figure 3 shows the autocorrelation functions for Model 3. A look at Figure 1 makes clear why the above specified approximation for the dynamics of the endogenous process for consumption is worse for the case where technology shocks are transitory, because the impulse-response of consumption to technology shocks is "hump-shaped". We therefore conclude that our postulated process is a good representation of the endogenous consumption growth dynamics for models with highly persistent technology shocks. ${ }^{24}$

\footnotetext{
${ }^{23}$ We assume the disturbance terms $\eta$ and $e$ to be i.i.d. normally distributed. The shocks we obtain when we estimate our postulated process for consumption growth from simulated data turn out to be very close to normal. They display mild heteroscedasticity.

${ }^{24}$ This conclusion relies on the assumption that the consumption process is covariance-stationary, which it is since the production function is constant returns to scale and preferences are homothetic. The autocorrelation function is then one of the fundamental time series representations. See, e.g., Hamilton (1994).
} 


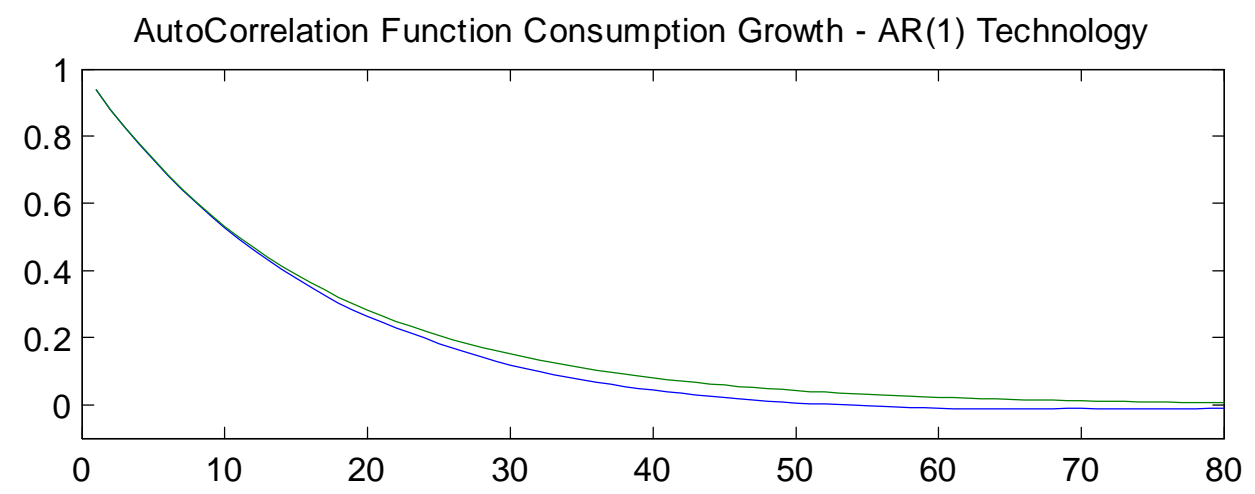

AutoCorrelation Function Consumption Growth - Random Walk Technology

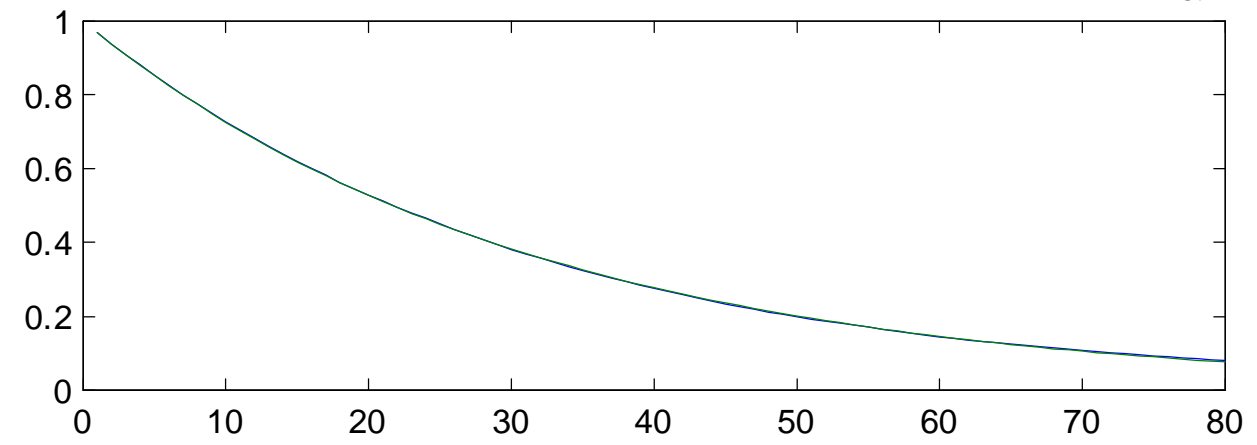

Figure 3: Autocorrelation Functions Consumption Growth Comparison of the autocorrelation function obtained directly from simulated data of Model 3 and the Baseline Model to the autocorrelation function implied by the postulated process for expected consumption growth which we have estimated from the same simulated data of Model 3 and the Baseline Model respectively. 


\subsection{Numerical Solution}

\subsubsection{Solution Algorithm}

We solve the following model:

$$
\begin{gathered}
V\left(K_{t}, Z_{t}\right)=\max _{C_{t}, K_{t+1}}\left\{\left[(1-\beta) C_{t}^{\frac{1-\gamma}{\theta}}+\beta\left(E_{t}\left[V\left(K_{t+1}, Z_{t+1}\right)^{1-\gamma}\right]\right)^{\frac{1}{\theta}}\right]^{\frac{\theta}{1-\gamma}}\right\}, \\
K_{t+1}=(1-\delta) K_{t}+\phi\left(\frac{I_{t}}{K_{t}}\right) K_{t}, \\
I_{t}=Y_{t}-C_{t}, \\
Y_{t}=Z_{t}^{(1-\alpha)} K_{t}^{\alpha}, \\
\ln Z_{t+1}=\varphi \ln Z_{t}+\varepsilon_{t+1}, \\
\varepsilon_{t} \sim N\left(\mu, \sigma_{z}\right) .
\end{gathered}
$$

We focus in this appendix on the case where $\varphi=1$. Since then the process for productivity is non-stationary, we need to normalize the economy by $Z_{t}$, in order to be able to numerically solve the model. To be precise, we let $\widehat{K}_{t}=\frac{K_{t}}{Z_{t}}, \widehat{C}_{t}=\frac{C_{t}}{Z_{t}}, \widehat{I}_{t}=\frac{I_{t}}{Z_{t}}$, and substitute. In the so transformed model all variables are stationary. The only state variable of the normalized model is $\widehat{K} .{ }^{25}$ We can work directly on the appropriately normalized set of equations and then re-normalize after having solved the model. ${ }^{26}$

The value function is given by:

$$
\widehat{V}\left(\widehat{K}_{t}\right)=\max _{\widehat{C}_{t}, \widehat{K}_{t+1}}\left\{\left[(1-\beta) \widehat{C}_{t}^{\frac{1-\gamma}{\theta}}+\beta\left(E_{t}\left[\left(e^{\varepsilon_{t+1}}\right)^{1-\gamma}\left(\widehat{V}\left(\widehat{K}_{t+1}\right)\right)^{1-\gamma}\right]\right)^{\frac{1}{\theta}}\right]^{\frac{\theta}{1-\gamma}}\right\}
$$

We parameterize the value function with a $5 t h$ order Chebyshev orthogonal polynomial over

\footnotetext{
${ }^{25}$ Note that $Z$ is not a state variable of the normalized model. This is due to the fact that we assume the autoregressive coefficient of the process for productivity $\ln Z_{t+1}=\rho \ln Z_{t}+\varepsilon_{t+1}$ to be unity: $\rho=1$. As a consequence, $\Delta Z$ is serially uncorrelated.

${ }^{26}$ In the paper we also report results for models where $\rho<1$. In this case we work directly on the above non-normalized set of equations. The state variables are then $K$ and $Z$. The solution algorithm is identical to the case where $\rho=1$.
} 
a $6 \times 1$ Chebyshev grid for the state variable $\widehat{K}$ :

$$
\Psi^{A}(\widehat{K})=\widehat{V}(\widehat{K})
$$

We use the value function iteration algorithm. At each grid point for the state $\widehat{K}$, given a polynomial for the value function $\Psi_{i}^{A}(\widehat{K})$, we use a numerical optimizer to find the policy $\left(\widehat{C}^{*}\right)$ that maximizes the value function:

$$
\begin{gathered}
\widehat{K}_{t+1}^{*} e^{\varepsilon_{t+1}}=\widehat{Y}_{t}-\widehat{C}_{t}^{*}+(1-\delta) \widehat{K}_{t} \\
\widehat{V}^{*}\left(\widehat{K}_{t}\right)=\left[(1-\beta)\left(\widehat{C}_{t}^{*}\right)^{\frac{1-\gamma}{\theta}}+\beta\left(E_{t}\left[\left(e^{\varepsilon_{t+1}}\right)^{1-\gamma}\left(\Psi_{i}^{A}\left(\widehat{K}_{t+1}^{*}\right)\right)^{1-\gamma}\right]\right)^{\frac{1}{\theta}}\right]^{\frac{\theta}{1-\gamma}},
\end{gathered}
$$

where Gauss-Hermite quadrature with 5 nodes is used to approximate the expectations operator. We use a regression of $\widehat{V}^{*}$ on $\widehat{K}$ in order to update the coefficients of the polynomial for the value function and so obtain $\Psi_{i+1}^{A}(\widehat{K})$.

\subsection{The Linear Factor Model}

The log stochastic discount factor is:

$$
m_{t+1}=\theta \ln \beta-\frac{\theta}{\psi} \Delta c_{t+1}-(1-\theta) r_{a, t+1}
$$

where $\theta=\frac{1-\gamma}{1-\frac{1}{\psi}}$. The process for consumption growth is:

$$
\begin{aligned}
\Delta c_{t+1} & =\mu+x_{t}+\sigma_{\eta} \eta_{t+1} \\
x_{t+1} & =\rho x_{t}+\sigma_{e} e_{t+1}, \\
\sigma_{\eta, e} & =\operatorname{corr}\left(\varepsilon_{t+1}, \eta_{t+1}\right) .
\end{aligned}
$$

For convenience, the shocks are normalized to have unit variance here, unlike in the main part of the paper. Linearizing the wealth-consumption ratio around it's steady state, we obtain (see Campbell, 1999, for a detailed derivation):

$$
r_{a, t+1} \approx \kappa_{0}+\kappa_{1} p c_{t+1}-p c_{t}+\Delta c_{t+1}
$$


where $p c_{t}$ is the $\log$ wealth-consumption ratio, $\kappa_{1}=\frac{\exp \left(\overline{p c_{t}}\right)}{1+\exp (\overline{p c t})} \approx 0.96$, and $\overline{p c_{t}}$ is the steady state log wealth-consumption ratio. Assuming log aggregate consumption growth $\Delta c_{t+1}$ to follow (56), Bansal and Yaron (2004) show that the log wealth-consumption ratio can be written as:

$$
p c_{t+1} \approx A_{0}+A_{1} x_{t+1}
$$

where

$$
A_{1}=\frac{1-\frac{1}{\psi}}{1-\kappa_{1} \rho} .
$$

Since $0<\rho<1,0<\kappa_{1} \rho<1$. Thus, $A_{1}>(<) 0$ if $\psi>(<) 1$. We substitute for $r_{a, t+1}$ in the $\log$ stochastic discount factor $(55)$ :

$$
\begin{aligned}
m_{t+1} \approx & \theta \ln \beta-\frac{\theta}{\psi} \Delta c_{t+1}-(1-\theta) \kappa_{0} \\
& -(1-\theta) \kappa_{1} p c_{t+1}+(1-\theta) p c_{t}-(1-\theta) \Delta c_{t+1} \\
\approx & \theta \ln \beta-(1-\theta) \kappa_{0}-\left(1-\theta+\frac{\theta}{\psi}\right) \Delta c_{t+1} \\
& -(1-\theta)\left[\kappa_{1} A_{0}+\kappa_{1} A_{1} x_{t+1}-A_{0}-A_{1} x_{t}\right] \\
= & \theta \ln \beta-(1-\theta) \kappa_{0}-\left(1-\theta+\frac{\theta}{\psi}\right) \Delta c_{t+1}-(1-\theta) A_{0} \kappa_{1}+(1-\theta) A_{0} \\
& -(1-\theta)\left[\kappa_{1} A_{1}\left(\rho x_{t}+\sigma_{e} e_{t+1}\right)-A_{1} x_{t}\right] \\
= & \theta \ln \beta-(1-\theta) \kappa_{0}-(1-\theta) A_{0} \kappa_{1}+(1-\theta) A_{0}-\left(1-\theta+\frac{\theta}{\psi}\right) \Delta c_{t+1} \\
& -(1-\theta) A_{1} \kappa_{1} \rho x_{t}-(1-\theta) A_{1} \kappa_{1} \sigma_{e} e_{t+1}+(1-\theta) A_{1} x_{t} .
\end{aligned}
$$

Let:

$$
\alpha=\theta \ln \beta-(1-\theta) \kappa_{0}-(1-\theta) A_{0} \kappa_{1}+(1-\theta) A_{0}
$$

Then:

$$
\begin{aligned}
m_{t+1} & \approx \alpha-\gamma \Delta c_{t+1}-(1-\theta) A_{1} \kappa_{1} \rho x_{t}-(1-\theta) A_{1} \kappa_{1} \sigma_{e} e_{t+1}+(1-\theta) A_{1} x_{t} \\
& =\alpha-\gamma \Delta c_{t+1}+(1-\theta) A_{1}\left(1-\kappa_{1} \rho\right) x_{t}-(1-\theta) A_{1} \kappa_{1} \sigma_{e} e_{t+1} .
\end{aligned}
$$

Write this as:

$$
m_{t+1} \approx a-b_{1} \Delta c_{t+1}-b_{2} e_{t+1}-b_{3} x_{t}
$$

where $b_{1}=\gamma, b_{2}=(1-\theta) A_{1} \kappa_{1} \sigma_{e}>0, b_{3}=-(1-\theta) A_{1}\left(1-\kappa_{1} \rho\right)<0$, since $(1-\theta) A_{1}=$ $\frac{\gamma-\frac{1}{\psi}}{1-\kappa_{1} \rho}$. Thus, if $\gamma>\frac{1}{\psi}$, then $(1-\theta) A_{1}>0$. By applying a standard log-linear first-order 
approximation (see, e.g., Yogo, 2006, for a similar application), the (not log) stochastic discount factor can be written as:

$$
\frac{M_{t}}{E\left[M_{t}\right]} \approx 1+m_{t}-E\left[m_{t}\right] .
$$

This in turn implies a linear unconditional factor model (see Cochrane, 2001):

$$
\begin{aligned}
E\left[R_{i, t+1}-R_{0, t+1}\right]= & b_{1} \operatorname{Cov}\left(\Delta c_{t+1}, R_{i, t+1}-R_{0, t+1}\right)+b_{2} \operatorname{Cov}\left(e_{t+1}, R_{i, t+1}-R_{0, t+1}\right) \\
& +b_{3} \operatorname{Cov}\left(x_{t}, R_{i, t+1}-R_{0, t+1}\right)
\end{aligned}
$$

where $R_{i, t}$ denotes the time $t$ gross return on asset $i$, and $R_{0, t}$ denotes the time $t$ gross return on a reference asset (the risk-free rate). Recall that $b_{1}, b_{2}>0, b_{3}<0$. The sign of the price of risk of each factor depends on the covariance matrix of the factors. The permanent shock model predicts that $\operatorname{cov}\left(\eta_{t+1}, e_{t+1}\right)>0$, which we confirm in the data. 